\title{
Impact of an extremely large magnitude volcanic eruption on the global climate and carbon cycle estimated from ensemble Earth System Model simulations
}

\author{
J. Segschneider ${ }^{1}$, A. Beitsch ${ }^{1, *}$, C. Timmreck ${ }^{1}$, V. Brovkin ${ }^{1}$, T. Ilyina ${ }^{1}$, J. Jungclaus ${ }^{1}$, S. J. Lorenz ${ }^{1}$, K. D. Six ${ }^{1}$, and \\ D. Zanchettin ${ }^{1}$
}

${ }^{1}$ Max-Planck-Institut für Meteorologie, Bundesstr. 53, 20146 Hamburg, Germany

*now at: Institute for Oceanography, KlimaCampus, University of Hamburg, Germany

Correspondence to: J. Segschneider (joachim.segschneider@zmaw.de)

Received: 25 May 2012 - Published in Biogeosciences Discuss.: 18 July 2012

Revised: 15 November 2012 - Accepted: 26 November 2012 - Published: 1 February 2013

\begin{abstract}
The response of the global climate-carbon cycle system to an extremely large Northern Hemisphere midlatitude volcanic eruption is investigated using ensemble integrations with the comprehensive Earth System Model MPIESM. The model includes dynamical compartments of the atmosphere and ocean and interactive modules of the terrestrial biosphere as well as ocean biogeochemistry. The MPIESM was forced with anomalies of aerosol optical depth and effective radius of aerosol particles corresponding to a super eruption of the Yellowstone volcanic system. The model experiment consists of an ensemble of fifteen model integrations that are started at different pre-ENSO states of a control experiment and run for 200 years after the volcanic eruption. The climate response to the volcanic eruption is a maximum global monthly mean surface air temperature cooling of $3.8 \mathrm{~K}$ for the ensemble mean and from $3.3 \mathrm{~K}$ to $4.3 \mathrm{~K}$ for individual ensemble members. Atmospheric $p \mathrm{CO}_{2}$ decreases by a maximum of $5 \mathrm{ppm}$ for the ensemble mean and by $3 \mathrm{ppm}$ to $7 \mathrm{ppm}$ for individual ensemble members approximately 6 years after the eruption. The atmospheric carbon content only very slowly returns to near pre-eruption level at year 200 after the eruption. The ocean takes up carbon shortly after the eruption in response to the cooling, changed wind fields and ice cover. This physics-driven uptake is weakly counteracted by a reduction of the biological export production mainly in the tropical Pacific. The land vegetation pool shows a decrease by $4 \mathrm{GtC}$ due to reduced short-wave radiation that has not been present in a smaller scale eruption. The gain of the soil carbon pool determines the amplitude of the $\mathrm{CO}_{2}$ per-
\end{abstract}

turbation and the long-term behaviour of the overall system: an initial gain caused by reduced soil respiration is followed by a rather slow return towards pre-eruption levels. During this phase, the ocean compensates partly for the reduced atmospheric carbon content in response to the land's gain. In summary, we find that the volcanic eruption has long-lasting effects on the carbon cycle: After 200 years, the ocean and the land carbon pools are still different from the pre-eruption state by $3 \mathrm{GtC}$ and $4 \mathrm{GtC}$, respectively, and the land carbon pools (vegetation and soil) show some long-lasting local anomalies that are only partly visible in the global signal.

\section{Introduction}

Volcanic super eruptions are very rare events of exceptional magnitude (Self and Blake, 2008) that have a strong impact on the Earth System. While this is relatively well known for the climate system, less research has been carried out to estimate the impact on the carbon cycle of both land and ocean and the resulting perturbations of the atmospheric $\mathrm{CO}_{2}$ content. Here, we investigate the short- and long-term (up to 200 years) impact of a super volcanic eruption on the Earth System including the global carbon cycle.

Well-known volcanic super eruptions are the 74 kyr B.P. Toba and the three extremely large eruptions at the geographical site of Yellowstone $\left(44^{\circ} \mathrm{N}, 110^{\circ} \mathrm{W}\right)$. Due to their large radiative forcing, super volcanic eruptions affect the climate system significantly (Jones et al., 2005; Self, 2006), 
(Robock et al., 2009; Timmreck et al., 2010). It has even been speculated for the $74 \mathrm{kyr}$ B.P. Toba eruption that the resulting climate perturbation brought modern human society close to the brink of extinction (Ambrose, 1998; Williams et al., 2009) due to the induced temperature decrease. However, care has to be taken when relating mass of ejected $\mathrm{SO}_{2}$ to climate perturbation. Timmreck et al. $(2010,2012)$ show that the volcanic maximum cooling does not increase linearly with the amount of total stratospheric sulphur injection, because of multiple limiting effects, including those based on radiation transmission (Beer-Bouguer-Lambert law) and the increase in particle size (Timmreck et al., 2012).

Large climatic perturbations have a potential to perturb the global carbon cycle. The latter is sensitive to changes in solar radiation, temperature, sea ice cover, and atmospheric and oceanic circulation. Model estimates of the impact of volcanic eruptions on climate and carbon cycle using comprehensive Earth System Models (ESMs) that include an interactive carbon cycle are a relatively recent achievement. The employed models represent not only the dynamical components of the climate system, but also the respective carbon cycle components, namely the land vegetation and soil as well as the carbonate chemistry and the ecosystem of the ocean. Such models can be forced with anomalies of AOD and effective radius of aerosol particles ( $\left.R_{\text {eff }}\right)$ corresponding to the sulfate aerosol cloud that develops after a volcanic eruption.

An earlier ESM study has been performed with the Hadley Centre Climate Model HadCM3 for the 1991 Mt. Pinatubo eruption (Jones and Cox, 2001). The authors show that the volcano induced cooling (about $0.4 \mathrm{~K}$ for the global mean surface temperature in their model, which is comparable to observed estimates, Thompson et al., 2009) is likely to have a measurable and significant effect on the carbon cycle. As the main mechanism, they identify globally reduced soil and plant respiration amplified by increased terrestrial primary productivity due to increased rainfall in the tropical rainforests of the Amazon and central Africa. For the ocean, the authors do not find significant variations in the uptake or release of carbon in response to the Mt. Pinatubo eruption.

Brovkin et al. (2010) analyse the carbon cycle response of the Max Planck Institute for Meteorology Earth System Model (MPI-ESM, Jungclaus et al., 2010) to the 1258 A.D. volcanic eruption. This is the largest known eruption in the period 800-2000 A.D., but the exact location is unknown. They simulate a global mean cooling of almost $1 \mathrm{~K}$ that lasts for a few years. In response to the cooling, the atmospheric $p \mathrm{CO}_{2}$ decreases by about $2 \mathrm{ppm}$. In contrast to the study of Jones and Cox (2001) also the ocean carbon pool responds to the volcanic forcing. It initially takes up about $1 \mathrm{GtC}$, but then quickly loses carbon to the atmosphere, compensating the carbon gain by the land biosphere.

Tjiputra and Ottera (2011) investigate the potential of volcanic eruptions to delay global warming and to alter the global carbon cycle in a scenario of rising atmospheric $\mathrm{CO}_{2}$ with the Bergen Earth System Model (BCM-C). In particular, they do simulate Pinatubo-like eruptions (Volcanic Explosivity Index VEI 6) every 5 years in one model run and Tambora like eruptions (VEI 7) every 25 years in another model run for the period 2000 to 2100 where $\mathrm{CO}_{2}$ emissions follow the IPCC-A2 scenario. They demonstrate that the smaller but more frequent eruptions have a larger impact on the carbon cycle than the less frequent larger eruptions. At the end of the integration in 2100, the atmospheric $p \mathrm{CO}_{2}$ is $46 \mathrm{ppmv}$ lower than in a control experiment without volcanic forcing.

Frölicher et al. (2011) investigate low-latitude volcanic eruptions of different strengths including super volcanic eruptions with the NCAR CSM1.4-carbon model for a 20 year period. Their forcing in terms of AOD at $55 \mu \mathrm{m}$ $\left(\mathrm{AOD}_{55 \mu \mathrm{m}}\right)$ perturbation varies from 1 to 100 times that of the 1991 Mt. Pinatubo eruption. The authors find a similar response of the climate - carbon cycle system to the AOD perturbation as Brovkin et al. (2010). Moreover, anomalies in the subsurface ocean prevail for 20 years (their model integration length). 20 years, however, is too short to investigate the long-term impact and the duration of the perturbation of the carbon cycle. Moreover, Frölicher et al. (2011) perform only one realisation for each forcing strength which makes it impossible to estimate the impact of climatic initial conditions at the time of eruption and relate this uncertainty to the volcanic signal.

In a recent discussion paper Rothenberg et al. (2012) describe the response of the Community Climate Model Version 3 (CCSM3) to tropical volcanic eruptions as represented by the time-varying volcanic forcing from Ammann et al. (2003) in the period 1870 to 2000 and the 1992 Pinatubo eruption in particular. They find that while their precipitation anomalies are comparable to observations, the biogeochemical response is smaller than observed and also smaller than modelled by Jones and Cox (2001). As they also found that the precipitation anomalies in Jones and Cox (2001) are too strong, they suspect that the correct carbon cycle anomalies in that paper may stem from incorrect climate anomalies. Moreover, Nemani et al. (2003) show that plant growth in the Amazon region is limited by radiation, not precipitation. From this, a decrease in net primary productivity (NPP) in the Amazon region in response to decreased radiation seems a more likely response to volcanic eruptions.

In this study, we advance beyond previous work by investigating a Yellowstone type Northern Hemisphere severe eruption as simulated by an atmospheric circulation and chemistry model in an ensemble simulation including the longterm response. We chose the geographical site of Yellowstone, because it is one of the most likely sites for such an eruption and has been restless since its last eruption (Wicks et al., 2006). We employ the MPI-ESM as described in Jungclaus et al. (2010). This model has been used to investigate the impacts of volcanic eruptions over the last millennium using AOD perturbations divided into 4 latitudinal bands (Brovkin et al., 2010). Our study advances over former studies in (i) that we obtain the volcanic forcing from 
an atmospheric circulation and chemistry model forced with $\mathrm{SO}_{2}$ emissions at the location of Yellowstone, (ii) in that we perform a 15 member ensemble by starting from different ENSO states and (iii) run the experiment over 200 years. We are, thus, the first to give an estimate of the behaviour of the Earth System for an explosive eruption at Yellowstone as it may occur in the foreseeable future (Wicks et al., 2006) with more realistic short-wave radiation perturbations than the 100 times Pinatubo AOD perturbation assumption. The study also provides a first estimate of the range of the responses of the climate system and carbon cycle to large volcanic eruptions depending on the state of the climate system at the time of explosion. As a further novelty, we investigate the long-term response of the system beyond 20 years.

\section{Model description, impact routes and experiment set-up}

\subsection{Model}

The MPI-ESM as used in our study consists of the atmospheric general circulation model (GCM) ECHAM5 (Roeckner et al., 2003), the land surface model JSBACH (Raddatz et al., 2007), the ocean GCM MPIOM (Marsland et al., 2003) and the marine biogeochemical model HAMOCC (MaierReimer, 1993; Maier-Reimer et al., 2005). We employ the same model as described in Jungclaus et al. (2010) and Brovkin et al. (2010). The spatial resolution of the atmospheric model is T31L19 $\left(96 \times 48\right.$, approximately $3.75^{\circ}$, and 19 layers between the surface and $10 \mathrm{~Pa}$ ), that of the ocean model GR30L40 (nominally $3^{\circ}$, with a higher resolution in the North Atlantic, and 40 layers, with higher vertical resolution in the upper part of the water column). The MPIESM response of the physical atmosphere-ocean model system to large volcanic eruptions is described in Zanchettin et al. (2011). As the MPI-ESM components are described in detail elsewhere, we only provide a short description of the model's land and ocean carbon cycle, mainly to allow a better understanding of the processes that will respond to the volcanic eruption.

The oceanic carbon cycle model HAMOCC works on the same grid as the physical ocean model. It simulates the full carbonate chemistry (Maier-Reimer, 1993) and a simplified, NPZD type, biological system (Six and Maier-Reimer, 1996). The latter consists of the nutrients (N) phosphate, nitrate, silicate and iron, phytoplankton $(\mathrm{P})$, implicitly divided between coccolithophores and diatoms depending on the availability of silicate. Grazing of phytoplankton by zooplankton (Z) and the sinking of detritus (D) are also part of the model. With regard to our analysis, it is important to keep in mind that (i) the solubility of $\mathrm{CO}_{2}$ in seawater depends mainly on the temperature, and (ii) the productivity of the marine ecosystem on availability of nutrients, short-wave radiation, and temperature. Moreover, it is the sinking of detri-

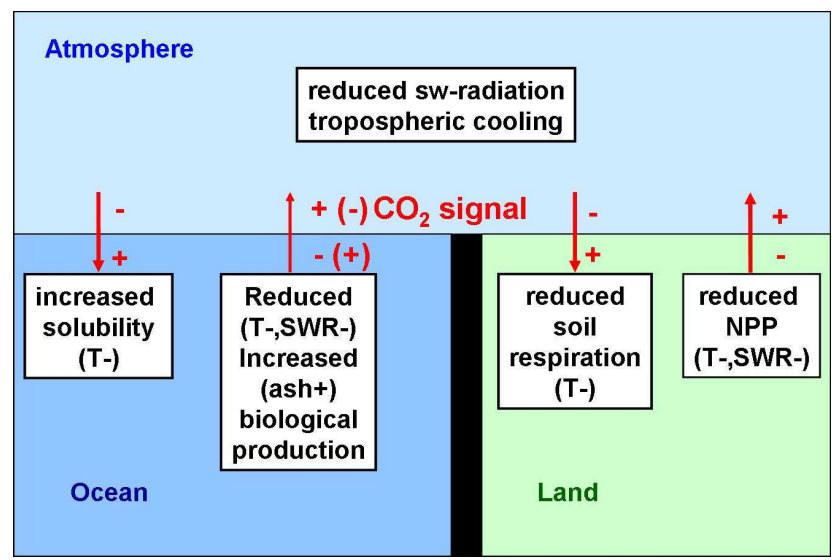

Fig. 1. Sketch of potential effects of volcanic eruptions on the carbon cycle as included in MPI-ESM. Fertilisation by ash is included for ocean only model set-up, not the ESM. ( $T-)$ signifies in response to negative temperature anomaly, (SWR-) in response to negative short-wave radiation anomaly, and (ash +$)$ in response to ash input from volcanic eruptions. Arrows indicate direction of anomalous $\mathrm{CO}_{2}$ fluxes, +/- a gain/loss of the respective reservoir, $(-) /(+)$ in response to increased ash deposition. NPP is net primary productivity, SWR - shortwave radiation, $T$ - temperature.

tus out of the surface ocean that determines the strength of the biological pump, not the biological production as such. Carbon fluxes between the ocean and the atmosphere are computed depending on the difference in partial pressure between the two components, and the piston velocity, which depends mainly on wind speed. Additionally, sea ice will inhibit any flux for entirely ice-covered grid cells.

The land surface component JSBACH operates with the same spatial and temporal resolution as the atmospheric model ECHAM (here T31). The vegetation is represented by several plant functional types (trees, grasses, shrubs and pastures), and photosynthesis and, hence, gross primary productivity depends on short-wave radiation, temperature, $\mathrm{CO}_{2}$ concentration and moisture availability. The soil carbon is described by one slow and one fast reacting pool. Accumulation of carbon in the soil pool due to litter fall is an instantaneous process, while the mineralisation rate of soil organic carbon is a function of temperature $\left(Q_{10}=1.8\right)$ and soil moisture.

\subsection{Potential effects of volcanic eruptions on climate and the global carbon cycle in MPI-ESM}

In the MPI-ESM, the volcanic eruption as represented by AOD and $R_{\text {eff }}$ perturbations has several effects on the climate and the carbon cycle (Fig. 1). In the atmosphere, the main effect is a reduction in short-wave radiation (SWR) due to increased aerosol loading with the associated cooling of the troposphere and, thus, also the land and ocean surface. Cooling of the ocean will increase the solubility of $\mathrm{CO}_{2}$ in sea water, driving an anomalous carbon flux from the atmosphere to 
the ocean. A reduction of the SWR and the cooling, on the other hand, will have a negative impact on marine biological production rates, thereby weakening the biological pump. This would drive an anomalous carbon flux from the ocean to the atmosphere. Ash input from the volcano could potentially fertilise the ocean (not included in the main experiment of this study).

For the land biosphere, a cooling will reduce soil respiration, driving a flux from the atmosphere to the soil. The land vegetation carbon pool, as for the ocean, will decrease in response to reduced SWR and temperature, potentially driving a flux from the land into the atmosphere. Changes in precipitation and wind patterns also have potential for changing carbon fluxes, but these are less straightforward to estimate even with regard to their sign. For a discussion of potential drivers of carbon cycle anomalies by volcano related processes not included in the model we refer to the discussion in Sect. 4.

\subsection{Experiment design}

We follow a two step approach as in Timmreck et al. (2010). First, the formation and temporal development of the volcanic aerosol and the corresponding radiative forcing from an initial injection of $\mathrm{SO}_{2}$ are simulated with the global aerosol atmospheric model MAECHAM5/ HAM (Niemeier et al., 2009) in T42L39 resolution. Important initialisation parameters for a volcanic super eruption, namely the stratospheric sulphur emission, the eruption height and the duration of the eruption are highly uncertain even though there exist some estimates about the ejected mass in terms of dry rock equivalent.

We, therefore, investigate a generic $\mathrm{NH}$ mid-latitude super eruption with a reasonable/likely parameter set up. We chose the same parameters as for the chemistry climate model study MAECHAM4/CHEM (Timmreck and Graf, 2006) and for the MPI-ESM study of the tropical Younger Toba Tuff eruption (Timmreck et al., 2010, 2012). The magnitude of the Younger Toba Tuff (YTT) and Yellowstone eruptions in terms of $\mathrm{SO}_{2}$ injection into the atmosphere is about 100 times that of the $1991 \mathrm{Mt}$. Pinatubo eruption $(17 \mathrm{Mt}$ $\mathrm{SO}_{2}$, Read et al., 1993). We, thus, assume an initial sulfur injection of $1700 \mathrm{Mt} \mathrm{SO}$. This $\mathrm{SO}_{2}$ was released in the MAECHAM5/HAM model over 10 days in June at the grid box corresponding to the geographical coordinates of Yellowstone $\left(44^{\circ} \mathrm{N}, 110^{\circ} \mathrm{W}\right)$ and the pressure level of $30 \mathrm{hPa}$ (ca. $25 \mathrm{~km}$ ). The volcanic forcing is then calculated online in terms of AOD and $\mathrm{R}_{\mathrm{eff}}$ for every grid point of the model and stored as monthly and zonal mean for a period of 4.5 years.

Because the aerosol optical depth (AOD) perturbation scales quite differently to eruption strength than the $\mathrm{SO}_{2}$ injection, the resulting AOD perturbation is much less than the assumption of 100 times Pinatubo. Timmreck et al. (2010) compute a scaling factor of only about 30 instead of 100 for the maximum global mean AOD perturbation. This reduction is mainly due to the formation of larger aerosols than for smaller scale eruptions. These aerosols fall out of the atmosphere more rapidly than smaller ones.

In a second step, the MPI-ESM is forced with the obtained $\mathrm{AOD}$ and $\mathrm{R}_{\mathrm{eff}}$ anomalies as 48 zonal means. To provide an estimate of the variability of the model system response, a 15 member ensemble is created by starting the model at different ENSO states of a $2000 \mathrm{yr}$ control integration. We chose to select the ENSO state of the model to generate our ensemble because, on interannual time scales, it has a large impact on the global climate (Penland et al., 2010) as well as on the carbon cycle (Winguth et al., 1994). The different states used correspond to strong El Niño, moderate El Niño, neutral, moderate La Niña and strong La Niña events. The control run was then analysed with regard to the ENSO state, and for each of the five classes three simulations are initialised at different times. The AOD perturbations are applied starting from month 6 of each model simulation. Each of the resulting 15 members is run for 200 years, resulting in a total of 3000 model years for the entire experiment. The long integration times are needed to investigate the long-term response of the carbon cycle components. We do not perform simulations with different eruption strength here, but will include some features of the model's response to the 1258 A.D. eruption described in Brovkin et al. (2010) in the discussion of model results.

We diagnose the model output with regard to climate parameters and the carbon pools over the entire 200 years by computing anomalies with respect to the respective years of the unperturbed control run rather than to compare them with the control run mean. Thus, we exclude anomalies arising from the internal long-term variability of the control run when computing anomalies. The method also assures that anomalies start with zero at the onset of the volcanic eruption. We will show time series of the anomalies for the ensemble mean and individual members, and plots of horizontal distribution of monthly mean ensemble mean anomalies at selected times. The times were selected by subjective analysis of 120 monthly mean anomaly plots for the first 10 years of the experiment.

\section{Results}

\subsection{Climate response}

First the climatic response of the model is described. Information about significance of results is given by grey shading in time series figures ( $\pm 2 \sigma$ level including the annual cycle) and stippling in maps where anomalies exceed the local $2 \sigma$ level of the control experiment for the respective month. The temporal evolution of the globally averaged surface air temperature (SAT) is shown in Fig. 2 for a) the entire 200 year period of each experiment and $b$ ) for the initial 20 years. We will use Fig. 2a to describe the temporal evolution of the SAT anomalies, and Fig. $2 b$ to better describe the magnitude of the 

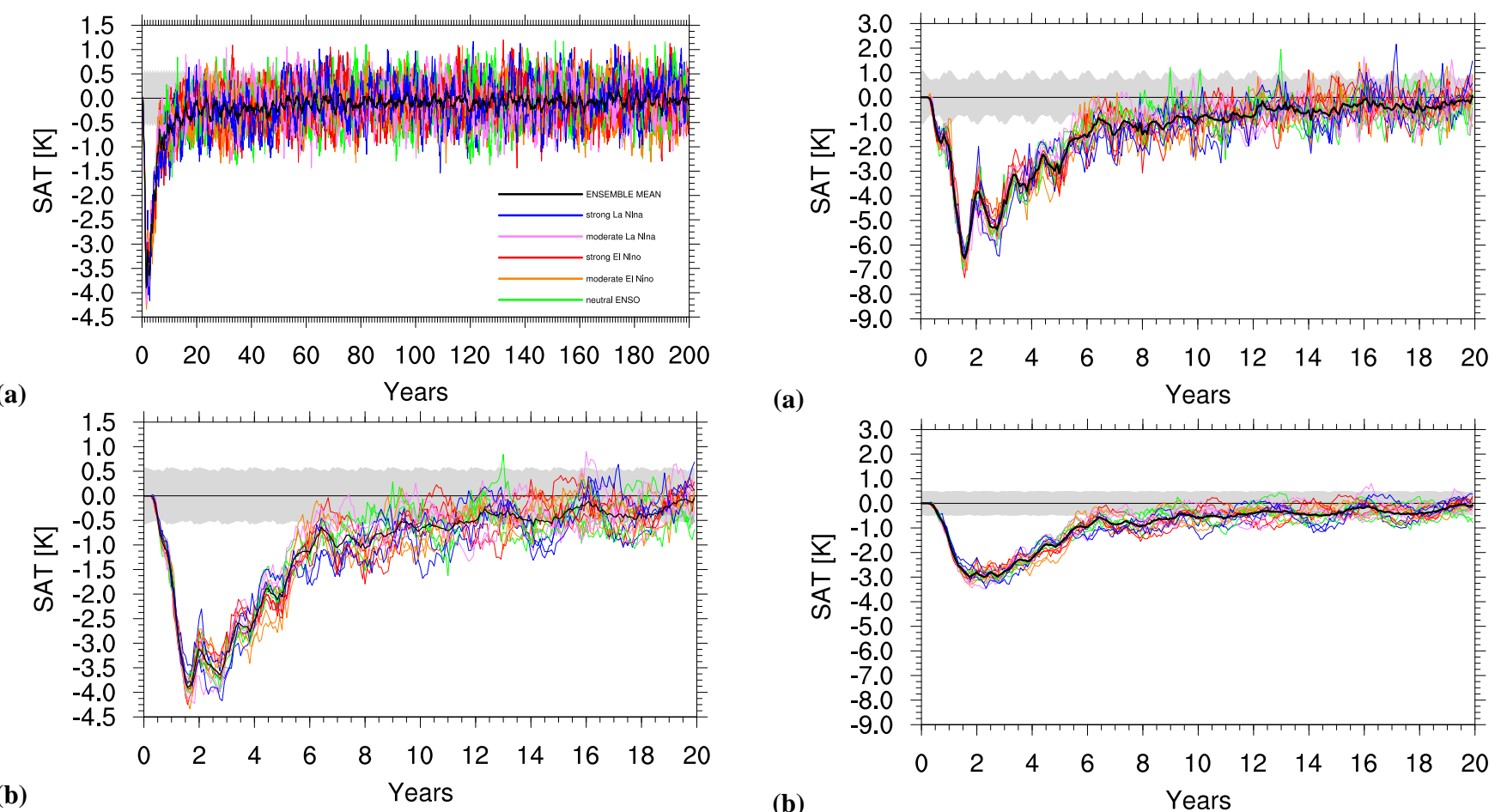

(a)

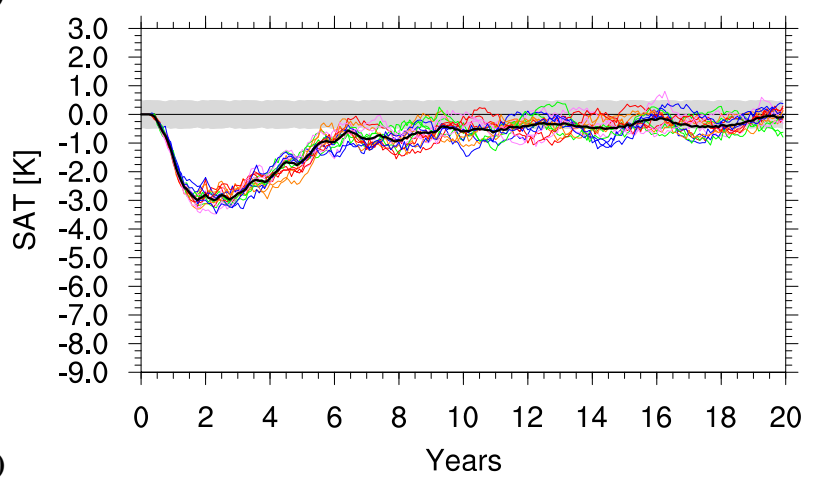

Fig. 2. Time series of global and monthly mean SAT anomalies (K) for (a) the entire 200 years of the model experiments and (b) a close-up of the first 20 years. Colours indicate the ENSO state of the control run at which the individual ensemble members were started: Green for neutral ENSO, dark blue for strong La Niña, pink for moderate La Niña, red for strong El Niño and orange for moderate El Niño. The grey shaded areas indicate the monthly mean $2 \sigma$-bar from the control experiment.

perturbations. SAT in all experiments drops rapidly to a minimum value within the first two years, followed by a relatively quick recovery over the next 5 years and then a slower return to pre-eruption levels (Fig. 2a). The ensemble mean anomaly (thick black line) is back within the $2 \sigma$-range of the control run (grey bar) after 10 years, but it takes more than 50 years before the ensemble mean anomaly is back to zero. The maximum ensemble mean cooling (Fig. $2 \mathrm{~b}$ ) is close to $-3.8 \mathrm{~K}$. Individual members can be up to $0.5 \mathrm{~K}$ colder or warmer, but there is no clear relation between the initial conditions and the resulting temperature anomaly of the ensemble members (see also Sect. 4). The global mean cooling for the ensemble mean is larger than $-2.5 \mathrm{~K}$ from the beginning of year 2 until the end of year 4 . The SAT perturbation averaged over all land points (Fig. 3a) is much stronger than the global mean cooling and SAT decreases by more than $7 \mathrm{~K}$, while the SAT mean over all ocean points decreases by only around $3 \mathrm{~K}$ (Fig. 3b).

Maps of short-wave radiation anomalies on the Earth's surface as a measure of the volcanic forcing are shown for the ensemble mean in Fig. 4a-d. Maximum anomalies are up to $-100 \mathrm{~W} \mathrm{~m}^{-2}$ in large areas and mainly negative as ex-

Fig. 3. Time series of global and monthly mean SAT anomalies over (a) land points only and (b) ocean points only for the first 20 years of the model integrations. The grey shaded area represents the monthly mean $2 \sigma$-bar from the control experiment. Colours indicate the initial conditions of the integrations as in Fig. 2.

pected, but also some limited areas of positive anomalies are present. These can develop because the volcanic perturbation from the aerosol cloud is modulated by forced changes in cloud cover (not shown) due to the alteration of the climate, but are rarely statistically significant (see, e.g., the area of positive SWR anomalies in the Eastern Equatorial Pacific at month 24, Fig. 4c). SWR perturbations are strongest between $30^{\circ} \mathrm{S}$ and $30^{\circ} \mathrm{N}$. Obviously, in the respective winter seasons, anomalies are zero polewards of the polar circles. 2 years after the eruption the volcanic forcing becomes weaker and the SWR anomalies become more heterogeneous (Fig. 4d).

The anomalies of SAT (Fig. 4e-h) largely resemble the SWR anomalies, indicating a local impact of reduced SWR mainly over land. Deviations from the pattern of the SWR anomalies (Fig. 4a-d), are caused by the larger thermal inertia of the ocean than for land. SAT drops by more than $10 \mathrm{~K}$ over some Northern Hemisphere continental regions, namely central North America and the Himalayan Plateau (Fig. 4f). The cooling is generally lower over the ocean but still statistically significant in most regions. As a consequence of the different thermal inertia for land and ocean, there is a pronounced temperature perturbation dichotomy with stronger cooling over the Northern Hemisphere and, in particular, in the Southern Ocean the cooling is only between $0 \mathrm{~K}$ and $2 \mathrm{~K}$ and rarely statistically significant. 

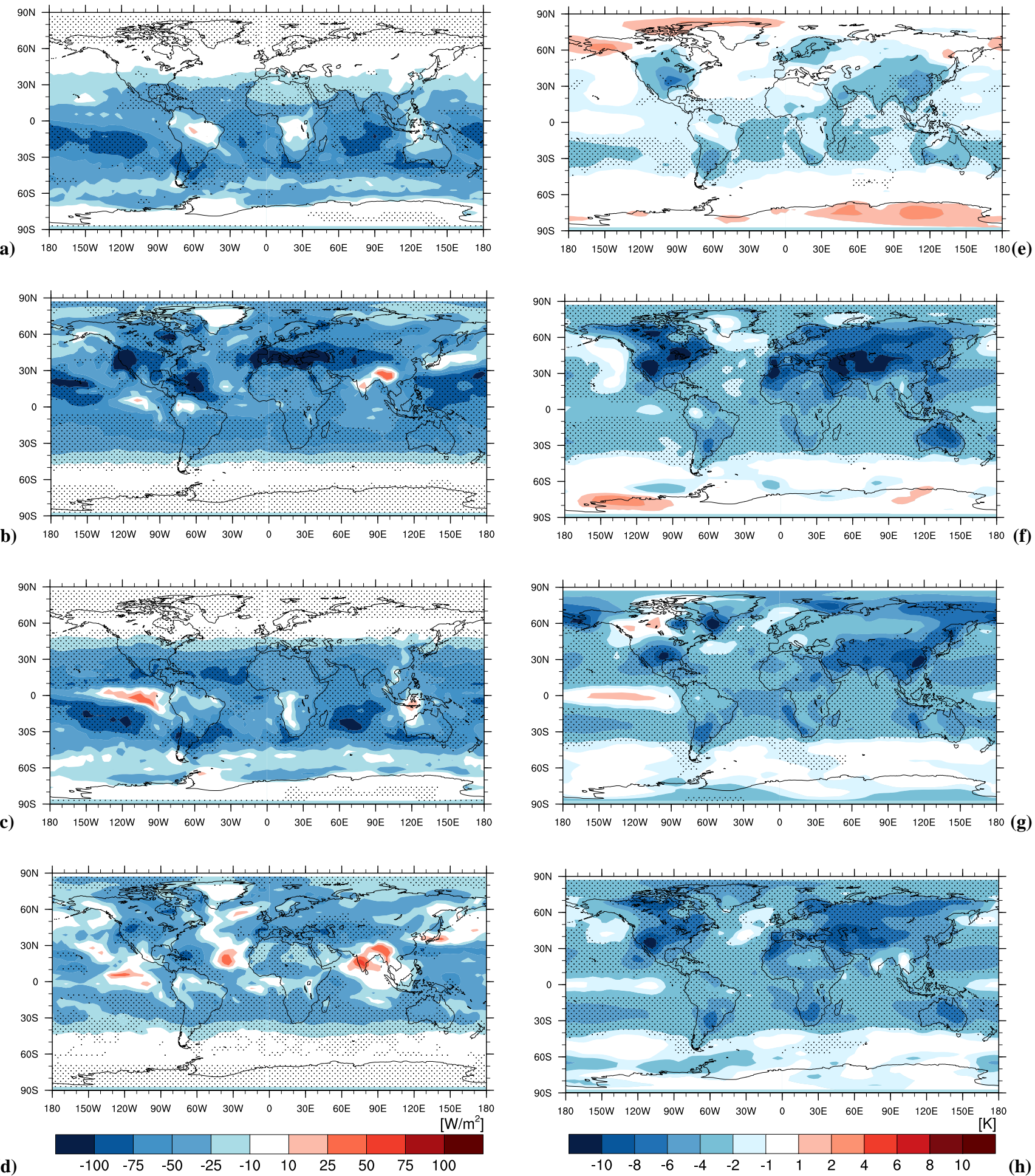

Fig. 4. Maps of ensemble and monthly mean anomalies of (a-d) short-wave radiation at the Earth's surface ([W $\left.\mathrm{m}^{-2}\right]$, left column) and (e-h) surface air temperature SAT ([K], right column). For (a, e) month 12 (December year 1), (b, f) month 18 (June year 2), (c, g) month 24 (December year 2), and (d, h) month 30 of the experiment (June year 3). Stippled areas indicate significance of anomalies based on the $2-\sigma$ criterion. 
(a)
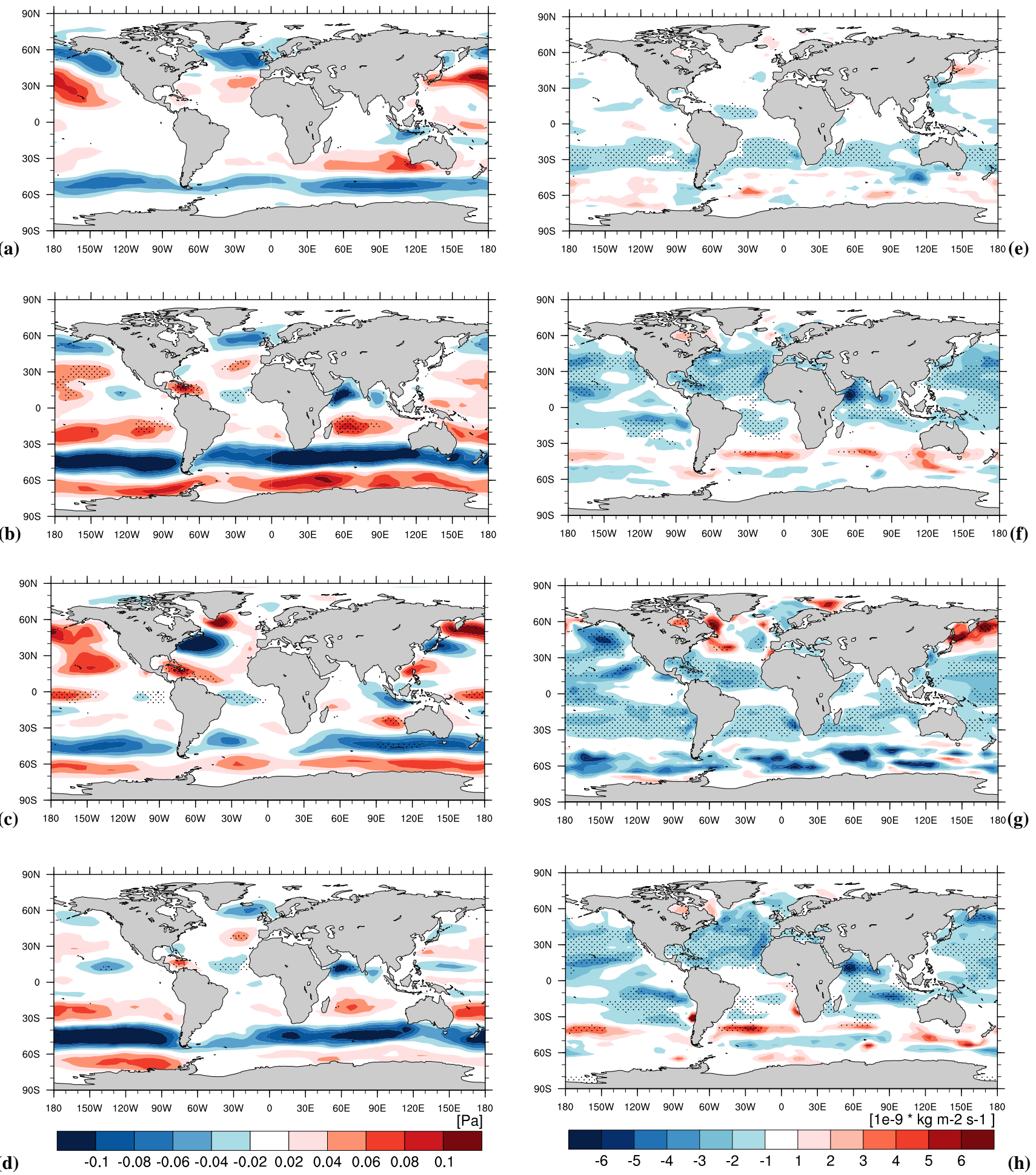

Fig. 5. As Fig. 4, but for (a-d) zonal wind stress $\tau_{x}$ (Pa) and (e-f) $\mathrm{CO}_{2}$ flux $\left(10^{-9} \mathrm{~kg} \mathrm{C} \mathrm{m}^{-2} \mathrm{~s}^{-1}\right.$ ) for (a, e) month 12 (December year 1 ), (b, f) month 18 (June year 2), (c, g) month 24 (December year 2), and (d, h) month 30 of the experiment (June year 3). Positive anomalies of the $\mathrm{CO}_{2}$ flux indicate an anomalous flux from the ocean to the atmosphere. 
(a)

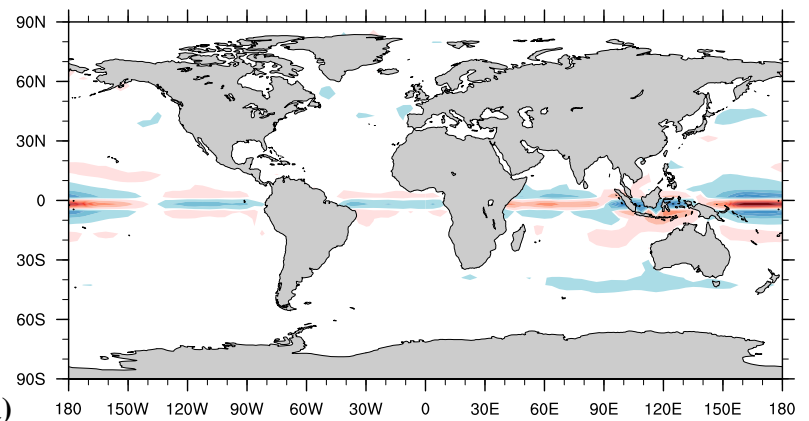

(b)
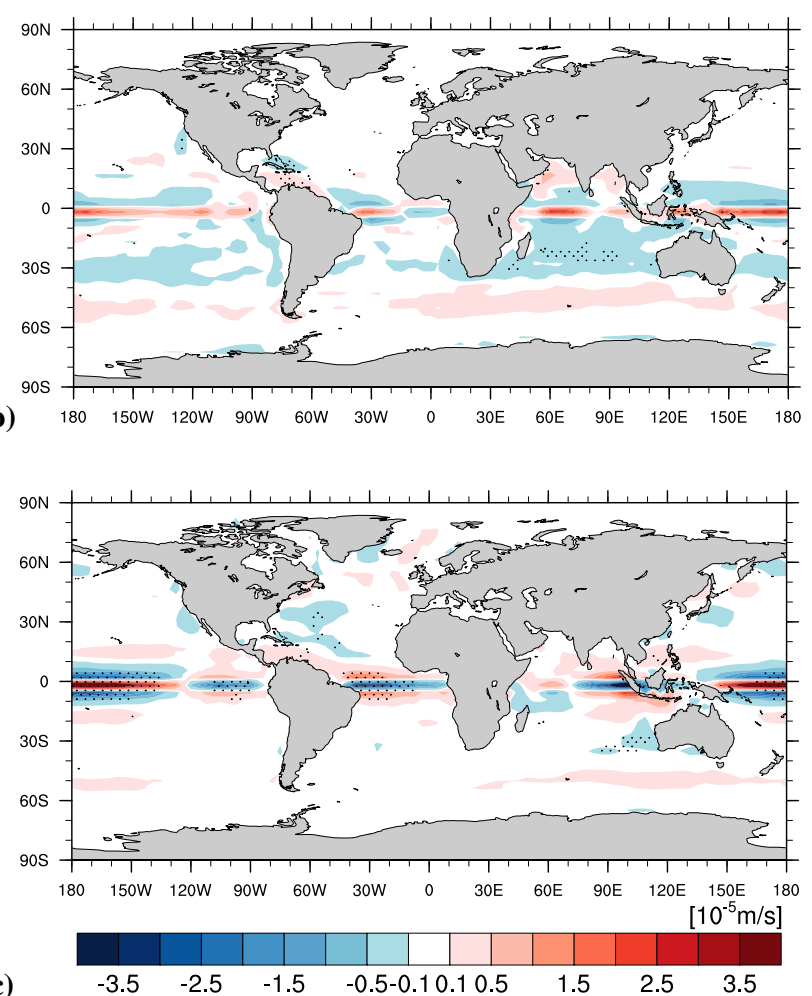

(c)

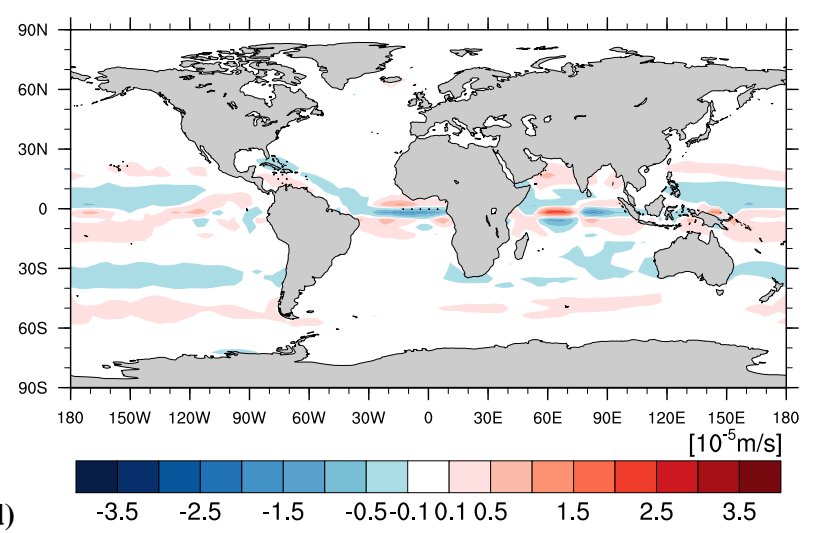

Fig. 6. As Fig. 4, but for Ekman pumping $\left[10^{-6} \mathrm{~m} / \mathrm{s}\right]$, for month 12 (a), 18 (b), 24 (c) and 30 (d) of the model integration. Positive anomalies indicate an anomalous upward flow.
The zonal wind stress $\tau_{x}$ (Fig. 5a-d) develops strong anomalies 12 months after the volcanic eruption: a negative anomaly spans the entire globe between $30-50^{\circ} \mathrm{S}$, and a band of positive anomalies is centred around $60^{\circ} \mathrm{S}$. This indicates a southward shift of the Southern Hemisphere westerlies, but the anomalies are not significant with regard to the internal variability of the control experiment. This anomalous pattern persists for about 2 years and then slowly becomes weaker. Even though the anomalies are not statistically significant, the shift has the potential to perturb the marine carbon cycle through upwelling of nutrients and carbon rich deeper waters as well as changing the piston velocity of gas exchange between ocean and atmosphere.

The supply of surface waters with nutrients as well as carbon rich subsurface waters depends on the subsurface concentration and the upwelling velocity. In Fig. 6 we show maps of Ekman Pumping anomalies. The strongest signal comes from the equatorial belt in all ocean basins, but it is statistically significant at the $2 \sigma$ level only in month 24 (Fig. 6c). The Western Pacific shows persistently positive anomalies, while the anomalies change sign in the Eastern Pacific and the Atlantic and Indian Ocean. North and south of the equator anomalies of opposite sign prevail. In the southern mid-latitudes weak negative anomalies can be seen and a tendency for slightly positive values in higher southern latitudes.

Anomalies in sea ice cover also have a potential to effect carbon fluxes: Any increase of sea ice cover as a result of the cooling will strongly inhibit carbon fluxes between ocean and atmosphere and suppress oceanic biological production. To estimate if this is important, we show time series of global sea ice cover in March (typical maximum ice extent on the Northern Hemisphere) and September (typical minimum ice extent on the Northern Hemisphere) in Fig. 7 and horizontal distributions of sea ice fraction anomalies in September of Year 2 and March of Year 3 (Fig. 8). Sea ice cover increases quickly from $15.5 \times 10^{6} \mathrm{~km}^{2}$ to a maximum of $20 \times 10^{6} \mathrm{~km}^{2}$ for individual ensemble members in response to the cooling in March and from $6.0 \times 10^{6} \mathrm{~km}^{2}$ to $11 \times 10^{6} \mathrm{~km}^{2}$ in September (Fig. 7a, b). At the time of maximum ice extension in the respective hemisphere, anomalies are largest in months 21 and 27 (Fig. 8a, b). Interestingly, larger than normal ice cover prevails for more than 10 years.

\subsection{Carbon cycle response}

\subsubsection{Globally integrated response}

The different compartments of the carbon cycle react differently to the climate perturbation. Fig. 9 shows timeseries and Fig. 10 carbon pool versus SAT for globally summedup anomalies in $\mathrm{GtC}$ and $\mathrm{K}$, respectively, for the atmosphere, ocean and land. For the land compartment, there is a further separation into soil and vegetation. In Fig. 10 only the ensemble mean is shown. 


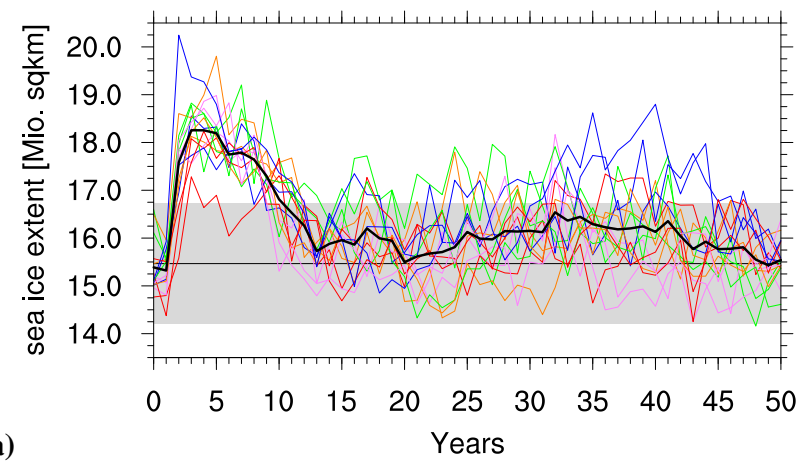

(a)

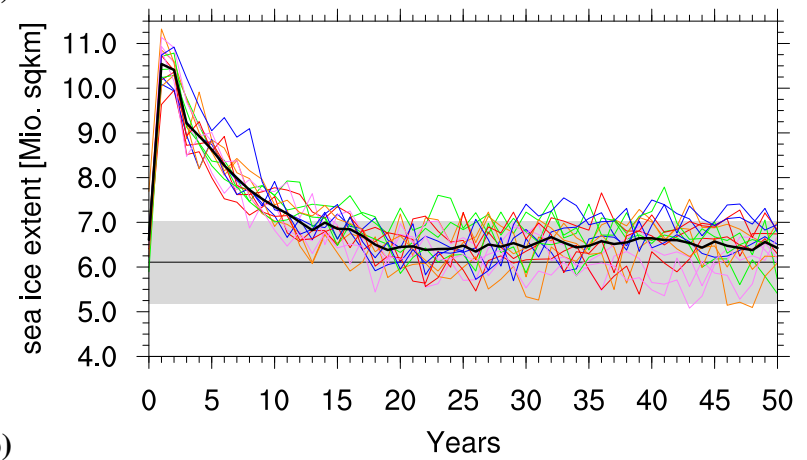

(b)

Fig. 7. Time series of global sea ice extent in (a) March and (b) September in $10^{6} \mathrm{~km}^{2}$. Colours as in Fig. 2.

The dominating signal in the atmosphere is a decrease of carbon content from year 3 to year 6 of around $10 \mathrm{GtC}$ for the ensemble mean and up to $14 \mathrm{GtC}$ for individual members (Fig. 9). This corresponds to a maximum decrease of atmospheric $p \mathrm{CO}_{2}$ by about $7 \mathrm{ppm}$ ( 5 ppm for the ensemble mean, see also Fig. 11). The decline is followed by a slow but steady return towards pre-eruption levels. This takes much longer than for SAT: The ensemble mean atmospheric carbon pool content is back in the $2-\sigma$ range of the control experiment after about 50 years. A small perturbation even remains until the end of the integration at year 200 (about -1 GtC).

The ocean compartment shows an initial gain of about 4 $6 \mathrm{GtC}$ having its maximum in year 4 . This is followed by a rapid loss of carbon to the atmosphere that results in values of about $4-8 \mathrm{GtC}$ below pre-eruption level around 50 years after the volcanic eruption. After this, a very slow recovery is simulated, so slow that at the end of the integration the ensemble mean oceanic carbon content is around $3 \mathrm{GtC}$ less than before the eruption.

The land compartment shows an initial decrease of up to $8 \mathrm{GtC}$ from year 2-4, mainly caused by a drop in the vegetation pool. This drop is accompanied by a smaller decrease in the soil pool in year 3-4, likely due to reduced litter input. After that, a rapid increase in land carbon up to $14 \mathrm{GtC}$ occurs, driven by the soil pool, followed by a slow return towards pre-eruption values. This longer term behaviour is also determined by the soil pool. The vegetation pool mainly shows weak fluctuations within the standard variation of the

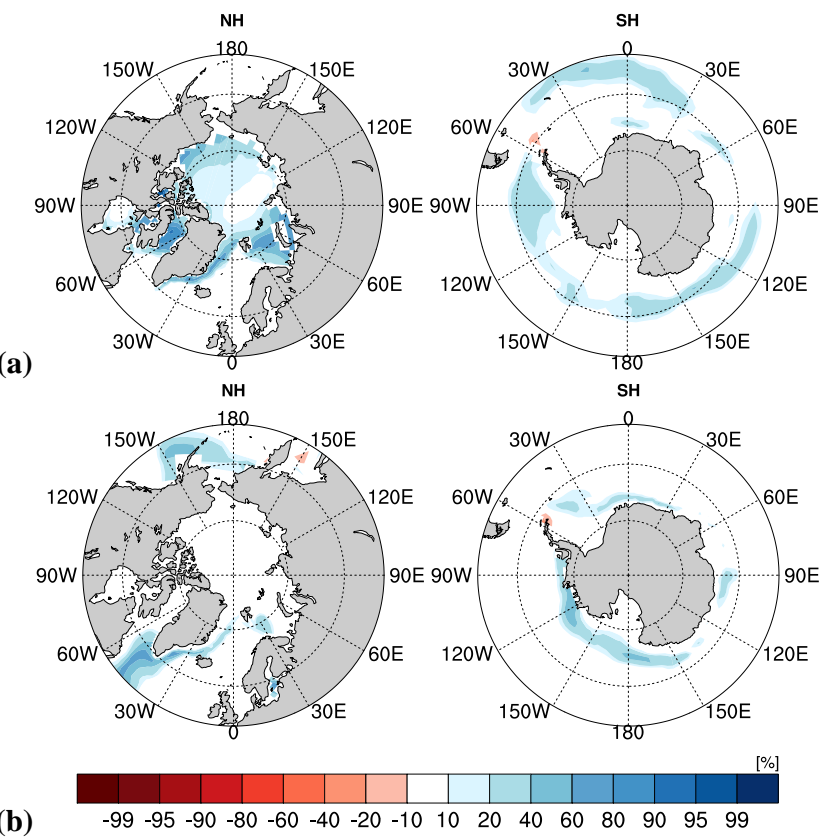

Fig. 8. Maps of ensemble mean anomalies of sea ice fraction [\%] for (a) September of year 2 and (b) March of year 3 of the model integration.

control run after year 4. At the end of the integration in year 200, the land carbon pool contains slightly more carbon ( $4 \mathrm{GtC}$ for the ensemble mean) than before the eruption.

Additional information can be gained from Fig. 10, which shows plots of the global mean carbon pool anomalies against SAT anomalies for the different compartments of the carbon cycle for the ensemble mean. To read the figure, one should follow the line from START using the time information as navigation aid. Figure 10a shows that, contrary to what one would expect, at the time of maximum temperature anomaly the atmospheric carbon content anomaly is close to zero due to compensating effects on the land and ocean carbon pools. Only from year 3 on the atmospheric $\mathrm{CO}_{2}$ anomaly becomes larger, at which time the SAT anomalies already become smaller. In year 6 the SAT anomaly is reduced from its maximum value to about $-1 \mathrm{~K}$ while the atmospheric carbon content anomaly has grown to $-11 \mathrm{GtC}$. After year 6 both SAT and atmospheric carbon content anomalies become smaller as can also be seen in Fig. 3 and Fig. 9a. The oceanic carbon pool (Fig. 10b) initially increases in concert with decreasing SAT, but then further grows as SAT anomalies remain in the range of -3 to $-4 \mathrm{~K}$. After year 4 , the ocean loses carbon even though SAT anomalies are still negative until from year 35 to 50 the negative anomaly is close to $-7 \mathrm{GtC}$. After year 50 the oceanic carbon content increases again, but remains below pre-eruption level as discussed above.

The soil carbon pool (Fig. 10c) initially gains up to $3 \mathrm{GtC}$ carbon as SAT decreases by $-4 \mathrm{~K}$, but towards the end of 

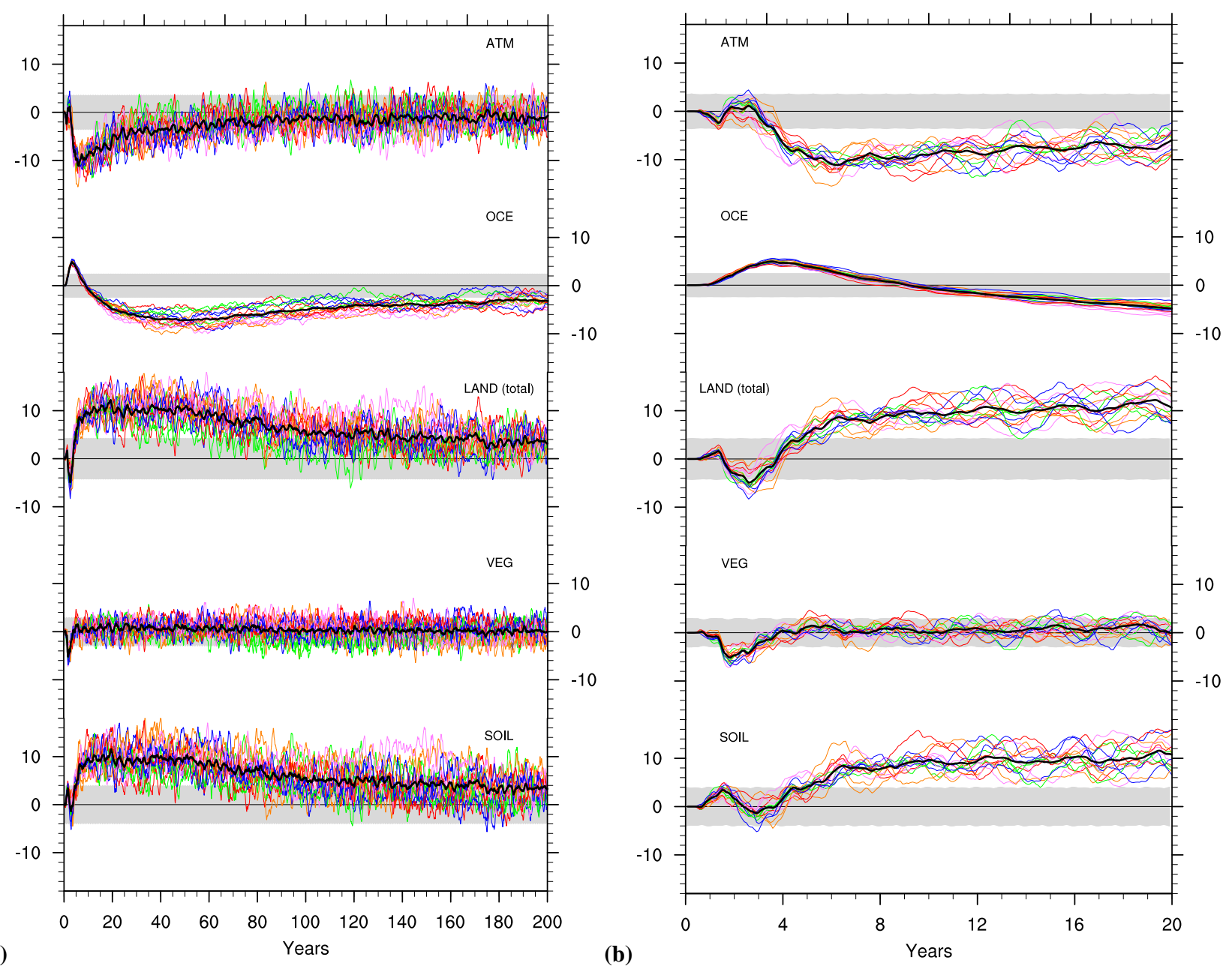

Fig. 9. Time series of annual mean carbon pool anomalies in GtC for (from top to bottom) the atmosphere (ATM), ocean (OCE), land vegetation and soil (LAND), and land vegetation (VEG) and land soil (SOIL) separately. The left column (a) shows the entire 200 years of the experiments, the right column (b) the first 20 years. The thick black line shows the ensemble mean, colours indicate initial conditions as in Fig. 2. The grey bars indicate the $\pm 2 \sigma$-interval from the control run (see text). The mean carbon pool inventories are: atmosphere $595 \mathrm{GtC}$, ocean $38102 \mathrm{GtC}$, land (total) $3004 \mathrm{GtC}$, vegetation $585 \mathrm{GtC}$, and soil $2419 \mathrm{GtC}$.

year 2 begins to lose carbon even though SAT anomalies are still in the range of -3 to $-4 \mathrm{~K}$. This interesting behaviour can be explained by the anomalies of the vegetation pool (Fig. 10d), which shows a loss of carbon with decreasing SAT and a gain of carbon with increasing SAT, as both temperature and photosynthesis anomalies are mainly driven by the SWR anomalies. The negative vegetation anomaly results in less litter input to the soil pool, and this temporarily overrides the inherent response of the soil pool to temperature. Only after year 3, when the negative SAT anomalies already become less strong, does the soil pool gain up to $10 \mathrm{GtC}$ of carbon even until SAT anomalies are back to zero. Also the final state of the soil pool differs from the initial state by almost $4 \mathrm{GtC}$.

The impact of the initial state of the model at the time of eruption for the carbon pools is similarly unclear as for
SAT. For example, when looking at the atmospheric pool in Fig. 9b, the El Niño started runs show a more immediate decrease than the La Niña started runs in the first 2 years, but the latter then continue to drop whereas the El Niño started runs show a temporal increase in carbon content. At the time of maximum anomaly, more La Niña started runs show larger than ensemble mean anomalies, but this is also the case for an El Niño started run. Likewise, one La Niña started run shows weaker than average response to the volcanic eruption. For the soil compartment, there is a tendency for the El Niño started runs to develop an initial positive anomaly up to year 2, but in the total land response this becomes less clear.

\subsubsection{Oceanic carbon cycle response}

In this section, we further focus on the marine carbon cycle, beginning with a description of the temporal and spatial 


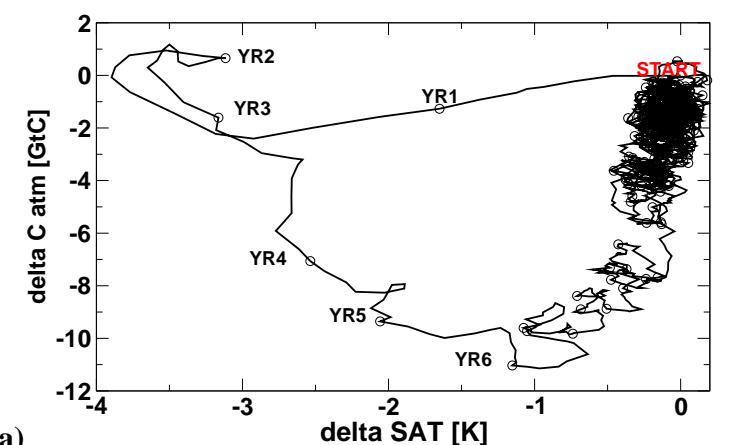

(a)

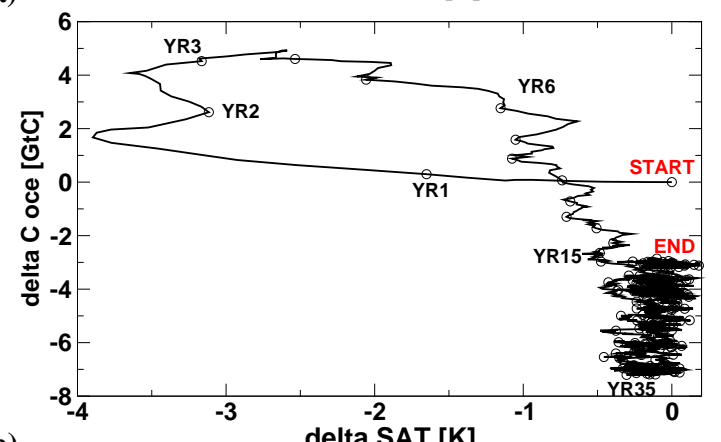

(b)

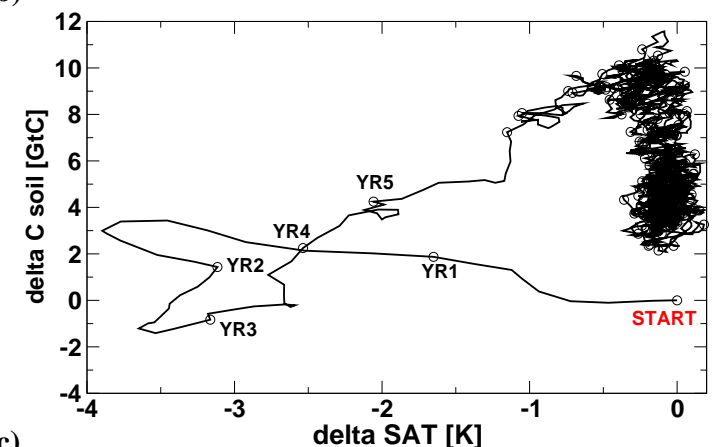

(c)

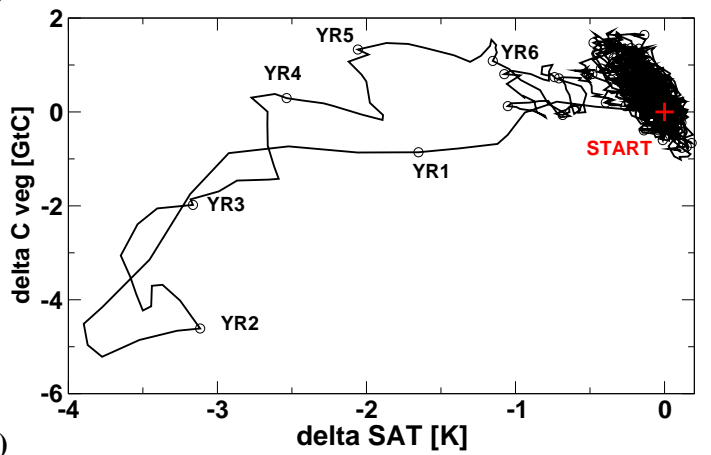

(d)

Fig. 10. Plots of ensemble mean SAT anomaly vs. ensemble mean anomaly of the carbon contents of (a) the atmosphere, (b) the ocean, (c) the soil, and (d) the terrestrial vegetation for $200 \mathrm{yr}$. Time information is given by circles at the end of each year and annotated for selected years. Note the different scales in the panels.

evolution of the sea-to-air carbon fluxes. Figure 5e-h shows selected maps of monthly mean air-sea carbon flux anomalies. Positive values indicate an anomalous flux from the ocean to the atmosphere. The anomaly of $\mathrm{CO}_{2}$ flux between

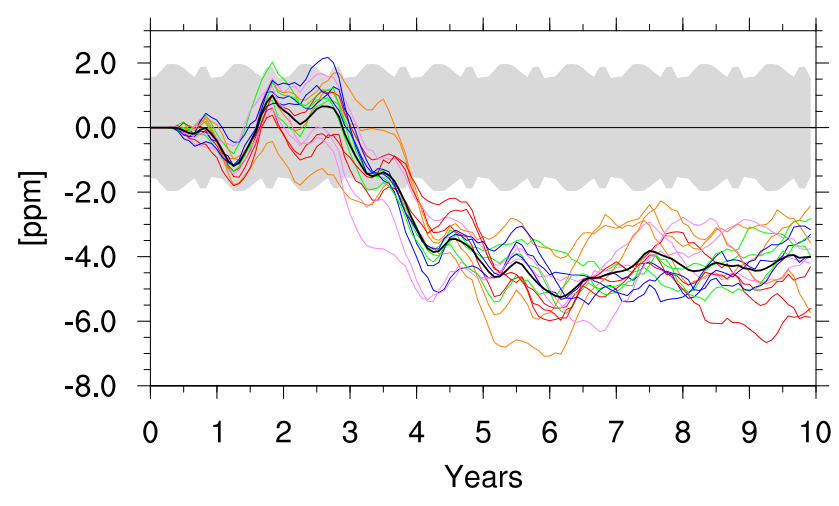

Fig. 11. Time series of monthly mean atmospheric $p \mathrm{CO}_{2}$ anomaly in ppm for the first 10 years of the experiment for the ensemble mean (black line) and individual members (coloured lines and grey shaded area as in Fig. 2)

ocean and atmosphere (Fig. 5e-h) shows, most pronounced in the Southern Ocean in southern winter, a tendency for negative anomalies (flux into the ocean) in areas of positive $\tau_{x^{-}}$ anomalies and positive anomalies (flux into the atmosphere) in areas of negative $\tau_{x}$-anomalies (Fig. 5b, f). These anomalies, however, are not statistically significant as internal variability is notoriously high in the Southern Ocean. In the low to mid-latitudes, however, the simulated $\mathrm{CO}_{2}$-flux anomalies are statistically significant even though they are much smaller. As the $\mathrm{CO}_{2}$-flux is driven not only by changing wind fields, but also by changes in temperature and export production it is not possible to identify wind stress as the dominant driving force in particular in southern summer (Fig. 5c, g).

In the northern winter of year $2 / 3$, anomalous fluxes from the ocean into the atmosphere show up in northern high latitudes. These are only partly related to $\tau_{x}$ (Fig. 5c, g). An explanation could be the increased sea ice cover (Fig. 8a) in response to the temperature drop. In the Southern Ocean the - still positive - anomalies shift from southern spring to southern winter, indicating that the physical carbon pump is becoming more dominant. Also in the following years, the Southern Ocean acts as a source of $\mathrm{CO}_{2}$ to the atmosphere. Initially, the strongest positive anomalies of the $\mathrm{CO}_{2}$ flux are apparent at the time of the respective spring blooms in the Southern and Northern Hemisphere, indicating weaker than unperturbed blooms or a delayed bloom, as $\mathrm{CO}_{2}$-flux anomalies become negative in December of year 2-3.

To investigate the driving mechanisms of the oceanic carbon cycle anomalies further we show time series of $\mathrm{CO}_{2}$-flux (Fig. 12) and export production (Fig. 13) anomalies for the first 6 years of each simulation as global sum for all ensemble members and the ensemble mean (Fig. 12a and Fig. 13a) and for distinct oceanic regions as ensemble mean only (Fig. 12b, $\mathrm{c}$ and Fig. 13b, c). The globally integrated ocean-atmosphere $\mathrm{CO}_{2}$ flux anomaly (Fig. 12a) is directed into the ocean beginning at the end of year 1 . At the beginning of year 2 the 


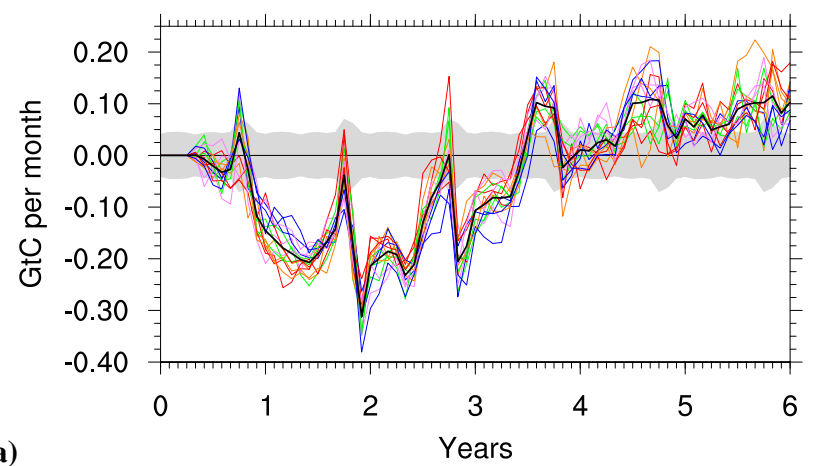

(a)

(b)
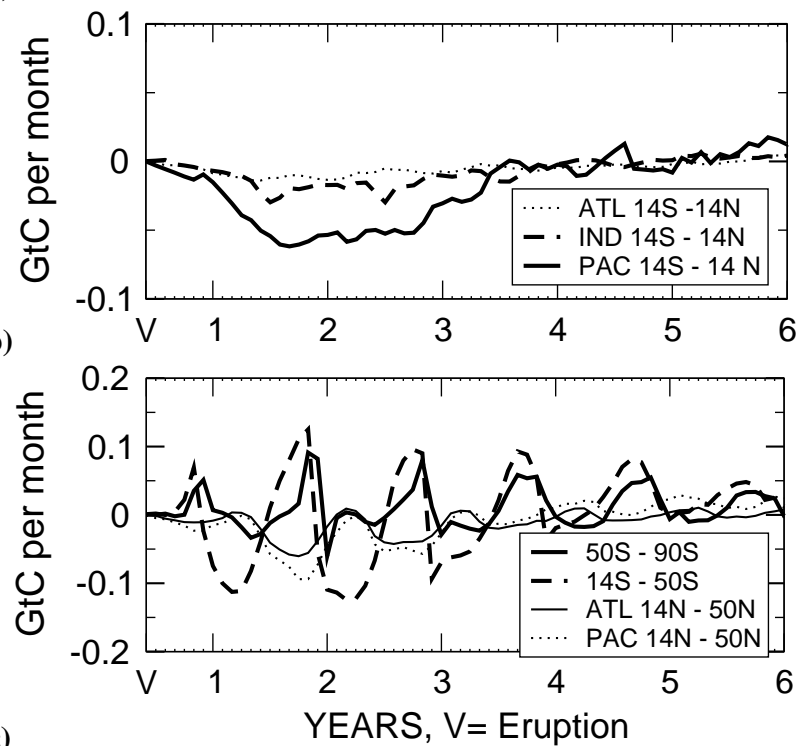

Fig. 12. Time series of monthly mean carbon flux anomalies from ocean to atmosphere in GtC per month for the first six years of the experiment. (a) globally averaged ensemble mean (black line) and individual members (coloured lines and grey shaded area as in Fig. 2), (b) ensemble mean averaged between $14^{\circ} \mathrm{S}$ and $14^{\circ} \mathrm{N}$ in the Atlantic (dotted), the Indian Ocean (dash-dotted) and the Pacific (solid). (c) ensemble mean for the Southern Ocean between $50^{\circ} \mathrm{S}$ and $90^{\circ} \mathrm{S}$ (bold), for all ocean basins between $14^{\circ} \mathrm{S}$ and $50^{\circ} \mathrm{S}$ (dash-dotted), and between $14^{\circ} \mathrm{N}$ and $50^{\circ} \mathrm{N}$ for the Atlantic (thin) and the Pacifc (dotted).

flux is about $0.1 \mathrm{GtC}$ per month. This value increases to about $0.2 \mathrm{GtC}$ per month for the ensemble mean over years 2 and 3 . This is much larger than the $2 \sigma$ interval from the control run (about $0.05 \mathrm{GtC}$ per month). Superimposed on this are positive spikes in Southern Hemisphere spring (October/November of year 2 and 3), and negative spikes in December/January of year 2 and 3 . This implies a dominating effect from the marine biology, consistent with a delayed Southern Ocean spring bloom, as already derived from the $\mathrm{CO}_{2}$ flux maps. Such a shift of the bloom may even have an impact on higher trophic levels as the supply of edible biomass will also shift in time.

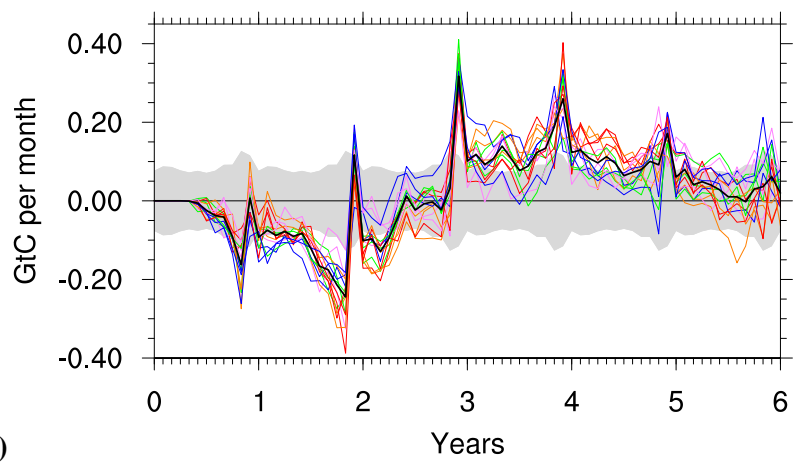

(a)

(b)
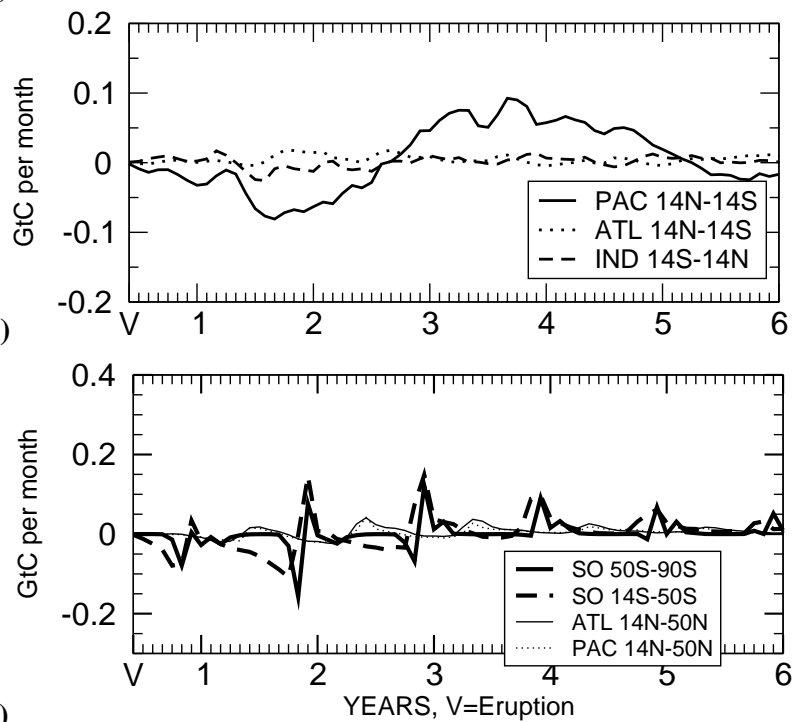

(c)

Fig. 13. As Fig. 12, but for the export flux of detritus at $90 \mathrm{~m}$ depth (the bottom of the euphotic zone in the model). Note the different scales.

Splitting the $\mathrm{CO}_{2}$-flux into different regions makes this even more clear (Fig. 12c). In the Southern Ocean, in particular, the positive/negative sequence shows up for some years, but also for the individual ocean basins between $14^{\circ} \mathrm{S}$ and $50^{\circ} \mathrm{S}$. The same delay of the spring bloom is apparent in the Northern Hemisphere, but with a phase shift of six month and less pronounced. This is also demonstrated by time series of the export production (Fig. 13). The global integral shows anomalously low export production in October/November and relatively high values in December (Fig. 13a). Both extremes leave the $\pm 2 \sigma$ interval. Looking into different regions (Fig. 13b,c) again reveals that the largest signals come from the Southern Ocean (Fig. 13c). Interestingly, while the negative anomalies disappear after year 3, the positive anomalies prevail for another 3 years, albeit weakening.

The tropical ocean reacts differently and the time series vary more smoothly, both for $\mathrm{CO}_{2}$-flux (Fig. 12b) and export production (Fig. 13b). Whereas the $\mathrm{CO}_{2}$-flux anomaly in the tropical Pacific returns to zero 3 years after the eruption, the export production shows positive anomalies from 2 years after the eruption until 5 years after the eruption. The amplitude 
of this positive anomaly is even slightly larger than the initial negative anomalies.

\subsubsection{Terrestrial carbon cycle response}

The terrestrial carbon cycle is further analysed by investigating the spatial distribution of anomalies of the vegetation and soil carbon pools. Maps of carbon storage anomalies for the ensemble mean are shown in Fig. 14 as annual means for year 2, 5, 50 and 200 of the model integration.

The vegetation carbon pool (Fig. 14a-d) develops statistically significant negative anomalies (stippled areas) in regions of temperate climate, and also in tropical regions in year 2 (Fig. 14a). In year 5, more positive but not statistically significant anomalies have developed in the temperate and tropical regions (Fig. 14b) while anomalies remain negative in mid to high northern latitudes. This pattern generally persists for the remainder of the model experiment and, thus, much longer than the climate perturbation (Fig. 14c, d). This is in sofar interesting as the global mean vegetation pool anomaly is close to zero already from year $\mathbf{5}$ onwards (Fig. 9). The maps demonstrate that locally, perturbations of the vegetation carbon pool persist for much longer. The local perturbations are largest around year 5 (Fig. 14b), but are still visible and statistically significant in a few locations in year 50 and even 200 (Fig. 14c, d). Note that, due to too wet conditions in the atmospheric model component for the desert regions of Australia, JSBACH tends to simulate higher than observed vegetation cover in central Australia and, thus, most likely too large a response of the Australian vegetation carbon pool to the volcanic forcing. Positive anomalies in the tropics are likely due to a cooling towards the temperature range of the growth optimum (see also Sect. 4.3), but these anomalies are not statistically significant as the interannual standard deviation is high in these areas (plot not shown).

For the soil pool (Fig. 14e-h), we find a similar anomaly pattern as for the vegetation, with a carbon gain in the tropical regions and carbon loss in the higher northern latitudes after the volcanic eruption developing from year 2 to year 5 (Fig. 14d, e). Here, the loss of soil carbon in higher latitudes is driven by reduced litter input from the slower growing vegetation, whereas in the tropical regions the reduced respiration in response to the cooling dominates the carbon content anomalies. In year 5 the positive anomalies are statistically significant mainly in the tropics, whereas the negative anomalies are statistically significant only in limited regions of South America. In year 5, maximum anomalies are more than $40 \mathrm{~mol} \mathrm{C} \mathrm{m}^{-2}\left[0.5 \mathrm{~kg} \mathrm{C} \mathrm{m}^{-2}\right]$ e.g., in the Amazon region. The soil carbon pool anomaly pattern persists for many years (Fig. 14g, h). In year 50, in the time range of the maximum global soil carbon anomalies (Fig. 9a), the negative anomalies have decreased in magnitude (e.g., in high northern latitudes) stronger than the positive anomalies in the tropics (Fig. 14g). From the global anomalies time series of soil carbon content (Fig. 9) it is evident that the reduced respi- ration in the tropical regions dominates the global long-term land carbon cycle response to the volcanic eruption. Any additional carbon in the soil pool in response to the volcanoinduced cooling is respired with the set time scale of respiration in the soil (100 years) once temperatures are back to normal. It is, therefore, more expected for the soil carbon than for the vegetation that the anomaly pattern persists for much longer than the temperature perturbation (Fig. 2).

\section{Discussion}

\subsection{Mechanisms leading to different responses of the land and ocean compartments}

We will first address the question why the land compartment reacts more sensitively to the volcano-induced climate perturbation than the ocean (see Sect. 3.2.1 and Fig. 9). A central point here is to understand how the ocean reacts to a change in the carbon content of the land component and vice versa. The dynamical link between the oceanic and terrestrial carbon pools is the atmosphere. Any change in the carbon content of the land or ocean pool will change the atmospheric carbon content. But, while the flux between ocean and atmosphere depends strongly on the difference in partial pressure between atmosphere and surface ocean, the flux between land compartment and atmosphere does not depend as strongly on the partial pressure of the atmosphere.

This holds for the system as considered here even though a weak impact of the ocean on the land could come from reduced $\mathrm{CO}_{2}$-fertilisation of the land biosphere as the ocean initially takes up $\mathrm{CO}_{2}$. But for the relatively small and short $p \mathrm{CO}_{2}$ changes induced by the oceanic uptake, these effects are only small: From the initial oceanic uptake of $6 \mathrm{GtC}$ the atmospheric $p \mathrm{CO}_{2}$ would decrease by $3 \mathrm{ppm}$. Norby et al. (2005), for various types of forest estimate an NPP increase of $23 \%$ for a doubling of atmospheric $\mathrm{CO}_{2}$ from $280 \mathrm{ppm}$ to $560 \mathrm{ppm}$. Assuming a NPP of $60 \mathrm{GtCa}^{-1}$, the impact would be a reduction of NPP by $0.15 \mathrm{GtC} \mathrm{a}^{-1}$.

A second question is why the strong cooling does not result in a more substantial uptake of $\mathrm{CO}_{2}$ by the ocean via the solubility pump. Broecker and Peng (1982) estimate a decrease of $10 \mathrm{ppm}$ in ocean partial pressure for a cooling by $1 \mathrm{~K}$ on decadal time scales. For our maximum cooling by $4 \mathrm{~K}$, this would mean a $40 \mathrm{ppm}$ decrease in ocean $p \mathrm{CO}_{2}$. This indicates that there is a potential for the solubility pump to play a strong role in response to temperature variations. We will now try to understand why the simulated oceanic uptake is weaker than could be inferred from the above estimate of the sensitivity of the solubility pump. First, the volcano induced cooling over the ocean is only half $(3 \mathrm{~K})$ of what it is over land $(6 \mathrm{~K})$, and it lasts only for a few years before becoming substantially weaker (Fig. 3). Both the relatively weak oceanic cooling and the time scale of the perturbation, thus, limit the oceanic response. In our experiment, the 
(a)
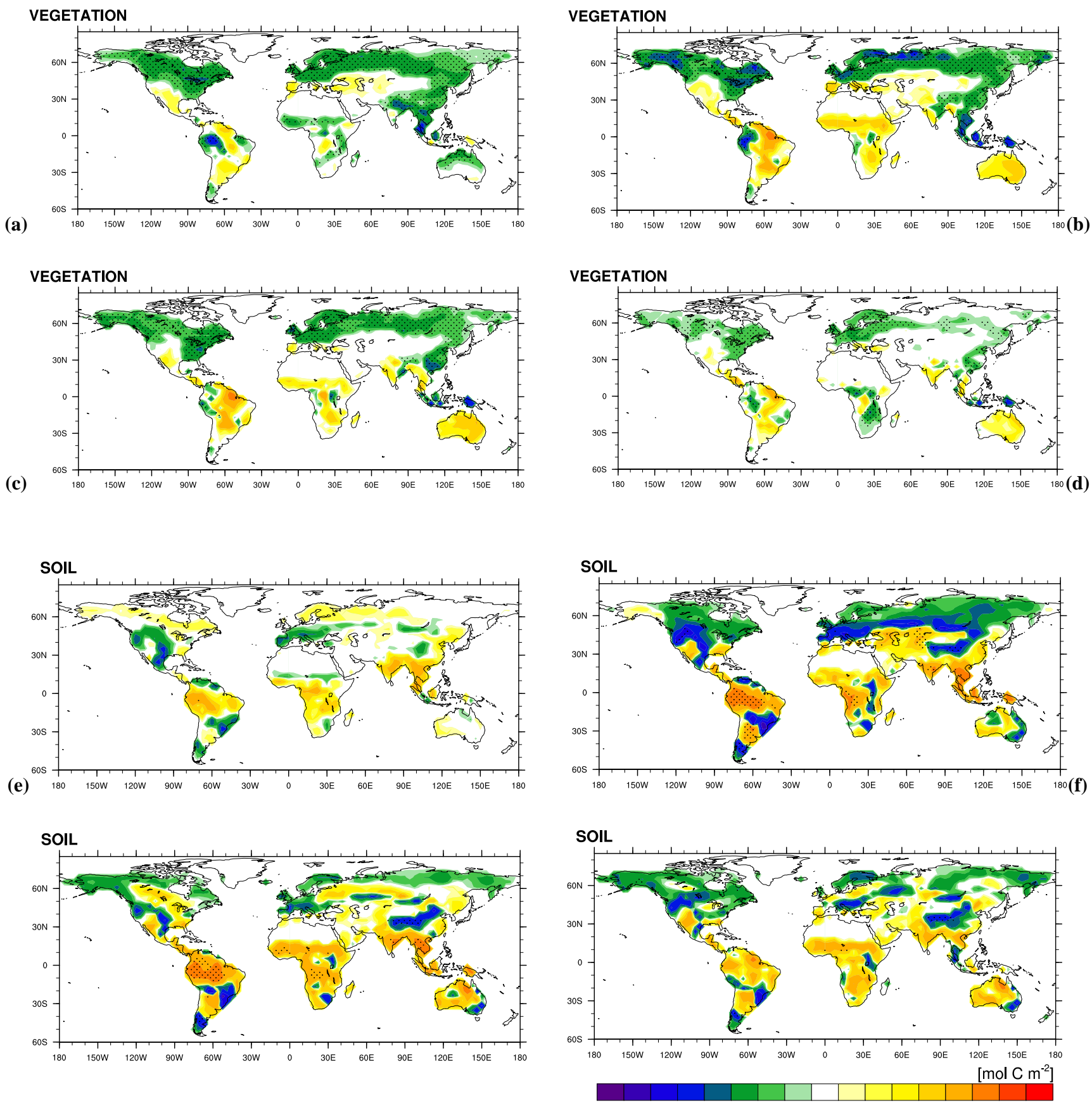

(g)

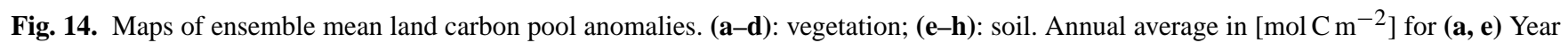
$2,(\mathbf{b}, \mathbf{f})$ Year $5,(\mathbf{c}, \mathbf{g})$ Year 50 and $(\mathbf{d}, \mathbf{h})$ Year 200 of the experiment. Stippled areas indicate significance of anomalies based on the 2- $\sigma$ criterion. 
physical pump is additionally counteracted by a decrease in export production at the time of maximum perturbation (2-3 years after the eruption, Sect. 3.2.2, Fig. 13). In the Southern Ocean anomalous carbon fluxes (Fig. 5e-h) are likely driven by changing zonal winds (Fig. 5a-d) and in the equatorial belt also by changed upwelling patterns (Fig. 6), but it is not possible to disentangle and quantify these effects with the current model set-up.

The cause-effect sequence after the volcanic eruption then is as follows: After an initial loss of vegetation, both the ocean and the land tend to take up more carbon as a result of the volcano induced cooling. The gain of carbon in the land carbon pool as simulated by the model decreases the atmospheric $p \mathrm{CO}_{2}$, causing a negative atmosphere-ocean partial pressure difference anomaly. This drives an immediate flux from the ocean to the atmosphere. As a result, the inherent oceanic behaviour as a sink of atmospheric carbon is overruled by the land compartment's gain and the ocean is turned into a source of carbon for the atmosphere five years after the eruption. The atmosphere has no carbon dynamics on its own and in this sense it merely is a passive reservoir that reacts to the fluxes from the land and the ocean. It should be kept in mind, however, that the dynamics of the atmosphere, in particular surface temperature, winds and precipitation, are the major drivers of the anomalies of land and ocean carbon reservoirs.

\subsection{Effects of different initial climate states on the magnitude of perturbation}

Additional information can be gained from performing an ensemble simulation e.g., by starting experiments from different climatic states such as ENSO as compared to a single realisation: For the physical system, the spread $(1 \mathrm{~K})$ of the ensemble for the maximum temperature anomaly after the eruption relates to about $25 \%$ of the simulated temperature response $(-3.3 \mathrm{~K}$ to $-4.3 \mathrm{~K}$, Fig. 2$)$. The coldest ensemble members in year 3 (anomaly of more than $-4 \mathrm{~K}$ ) are initialised from a moderate La Niña, and one moderate and one strong El Niño. In year 4, the coldest member is initialised from a strong La Niña, and the cooling is also stronger than $-4 \mathrm{~K}$, indicating that not only the amplitude, but also the timing of the maximum cooling can vary considerably amongst ensemble members. Deviations of the neutral ENSO initialised runs from the ensemble mean temperature anomaly are often as large as for other initialisations, but neutral ENSO runs seldom form the boundaries of the ensemble. In summary, this indicates that one could misinterpret the amplitude of the maximum cooling by up to $25 \%$ and the timing by one year when performing only a single realisation of the volcanic perturbation. Moreover, it cannot be argued that starting from neutral ENSO conditions would result in a response similar to the ensemble mean.

This holds even more for the carbon cycle response, in particular for the land compartment: individual ensemble mem- bers show maximum negative perturbations that range from zero to $-8 \mathrm{GtC}$ e.g., during year 3 , when the ensemble mean perturbation is up to $-4 \mathrm{GtC}$. This large range compared to the ensemble mean perturbation originates from both the vegetation and the soil pool (Fig. 9). For the ocean, the carbon content of individual ensemble members deviates by only $\pm 1 \mathrm{GtC}$ or $20 \%$ from the ensemble mean at the time of maximum perturbation ( $5 \mathrm{GtC}$, Fig. 9 year 4 ). For the marine biology, the temporal shift of the spring bloom is a robust feature across all ensemble members (Fig. 13a), but the amplitude of the anomalies of single members can be almost twice as large as for the ensemble mean (e.g., near the end of year 2).

Also for atmospheric $p \mathrm{CO}_{2}$ the spread of the perturbations is larger compared to the maximum anomaly than for global mean temperature ( $4 \mathrm{ppm}$ spread compared to a signal of 3$7 \mathrm{ppm}$ and an ensemble mean anomaly of about $5 \mathrm{ppm}$, i.e., $40 \%$ of the signal; Fig. 11). Most of this spread results from the land carbon pool, which can be explained by the larger amplitude and spread of the temperature anomalies over land compared to over the ocean (Fig. 3). This also indicates the need for ensemble simulations that sample the climate system state at the time of eruption when investigating the response of the Earth system to volcanic eruptions.

\subsection{The role of volcanic eruption magnitude}

The 1258 A.D. volcanic eruption ejected an estimated $260 \pm 60 \mathrm{Tg}$ of $\mathrm{SO}_{2}$ (Oppenheimer, 2003), indicating that the Yellowstone eruption is larger by a factor of 5.3-8.5. We find that the Yellowstone-like eruption differs by only a factor of 4 in the amplitude in the climatic signal $(-4 \mathrm{~K}$ and $-1 \mathrm{~K}$ for Yellowstone and 1258 A.D., (Brovkin et al., 2010), respectively) and even by only a factor of 2.5 in atmospheric $p \mathrm{CO}_{2}$ (maximum anomalies of $-5 \mathrm{ppm}$ and $-2 \mathrm{ppm}$, respectively).

When trying to explain this nonlinearity in the response of the carbon cycle to eruption magnitude, one needs to take into account the complex dependencies of the climate system and carbon cycle components. First, the nonlinearity between eruption strength and short-wave radiation perturbation needs to be taken into account to obtain a realistic climate perturbation as discussed in the Introduction. Second, the complex dependencies of mainly the land carbon system are of importance. Photosynthesis and, hence, gross primary productivity of the land biosphere depends on temperature, shortwave radiation, water availability and atmospheric $p \mathrm{CO}_{2}$. The dependence of photosynthesis on temperature is represented by a steep increase between $0{ }^{\circ} \mathrm{C}$ and about $18^{\circ} \mathrm{C}$, a weak dependency in the range of the growth optimum $\left(18-25^{\circ} \mathrm{C}\right)$ and a decrease for temperatures above $25^{\circ} \mathrm{C}$. No photosynthesis occurs below sub-zero temperatures. Consequently, a volcano induced temperature change will have different effects depending on the local climatic conditions. On one side, shifting the local temperature below the freezing point will inhibit any photosynthesis and on 
the other side a decrease in temperature might even cause an increase. Additionally, the effect depends on the type and abundance of vegetation at the location of temperature perturbation.

A second way of affecting the land vegetation pool comes from the radiation (usually phrased fPAR, fraction of photosynthetically active radiation). A reduction of fPAR due to the volcanic eruption decreases NPP more linearly than temperature (e.g., Fig. 3 in Bondeau et al., 1999). The relationship between temperature and SWR is nonlinear again due to, for example, the thermal inertia of the ocean and the dampening heat fluxes. A larger volcanic eruption will, therefore, have a stronger impact on SWR than on temperature compared to a smaller eruption. It also will shift temperatures below the optimum range in larger areas, and limit the growing season in high latitudes. Additional effects arise from changed precipitation patterns due to changes in atmospheric circulation and reduced evaporation from stomata as temperature decreases. It is, thus, evident that the dependency of land vegetation pool perturbations on eruption strength is highly nonlinear, but not straightforward to quantify.

For the two eruptions considered here, the much stronger Yellowstone eruption triggers a negative anomaly of the terrestrial vegetation in the first 2-3 years (Fig. 9) after the eruption which is not present in the 1258 A.D. eruption. The vegetation develops negative anomalies in the Yellowstone case mainly in the tropics and the northern boundaries of the boreal forests of Canada and Russia (Fig. 14a) which are not present for the 1258 A.D. eruption (Fig. 4b in Brovkin et al. (2010)).

Also for soil respiration the relationship between temperature and turnover times is nonlinear and additionally depends on soil moisture. Changes in the vegetation pool are transferred to the soil carbon pool by changes in litter input, and as a consequence changes in the soil carbon pool also depend nonlinearly on eruption strength. Here the pattern of the soil response is similar for Yellowstone and 1258 A.D., but the amplitude is much larger for Yellowstone (more than $40 \mathrm{~mol} \mathrm{C} \mathrm{m}^{-2}$ for Yellowstone in the Amazon region, Fig. 14f compared to $15 \mathrm{~mol} \mathrm{C} \mathrm{m}^{-2}$ for 1258 A.D., Fig. $4 \mathrm{c}$ in Brovkin et al. (2010)).

Finally, stronger atmospheric cooling from larger eruptions will drive larger compensating heat fluxes from the ocean, thus, dampening the cooling. While the marine ecosystem showed no significant response for the 1258 A.D. eruption, the much stronger Yellowstone-like eruption causes a reduction of the marine export production outside the range of the natural variability and a retardation of the spring plankton bloom in both hemispheres in the 2 years after the eruption (Fig. 13).

The initial drop in photosynthesis and the resulting loss of carbon of the vegetation pool is overcompensating the temperature driven soil pool gain of carbon, resulting in a net loss of carbon for the land pool (Fig. 9). At the same time, the ocean compartment gains carbon due to cooling after the
Yellowstone eruption. As a consequence, the perturbations of the atmospheric $p \mathrm{CO}_{2}$ in the first five years after the eruption are fairly small. In fact, when averaged over the first five years as in Brovkin et al. (2010) they are in the same range as the 2 ppm for the 1258 A.D. eruption (Fig. 11).

Unfortunately it is not possible to derive at a general relationship between the magnitude of volcanic eruptions and perturbation of the carbon cycle. Multiple experiments with comprehensive models are needed, such as in Frölicher et al. (2011). An indication for the nonlinearity of the land carbon cycle in their model is given in their Fig. 1e, where the steady increase of the land carbon pool after the volcanic eruption is temporarily interrupted - indicating a loss of the vegetation pool - for the 50 and $100 \times$ Pinatubo experiments. But this threshold will depend on the model's carbon cycle sensitivity which can be quite different for individual models as discussed in the next section.

\subsection{Carbon cycle sensitivity and carbon cycle-climate feedback}

When comparing our results to the study of Frölicher et al. (2011), we find that the sensitivity of the carbon cycle of the MPI-ESM is lower than that of the NCAR CSM1.4-carbon. The MPI-ESM response of atmospheric $p \mathrm{CO}_{2}$ to a cooling of $3.3 \mathrm{~K}-4.3 \mathrm{~K}$ is a decrease by $4-7 \mathrm{ppm}$, while for the NCAR CSM4.1 for a cooling of $2.2 \mathrm{~K}$ it is about $8 \mathrm{ppm}$ and for a cooling of $4 \mathrm{~K}$ it is close to $12 \mathrm{ppm}$ (10x Pinatubo case, Frölicher et al., 2011). This may be due to the temporal evolution of the land vegetation: While in the MPI-ESM, there is an initial decrease of the vegetation pool of $4 \mathrm{GtC}$ at the time of maximum ocean uptake (thereby limiting the atmospheric $p \mathrm{CO}_{2}$ anomaly), in the NCAR CSM1.4-carbon such a temporal behaviour only occurs for the 50 and 100x Pinatubo case (with a maximum cooling of $6 \mathrm{~K}$ and $8 \mathrm{~K}$, respectively, compared to $3.3 \mathrm{~K}-4.3 \mathrm{~K}$ for our $100 \mathrm{x}$ Pinatubo cases).

Climate-carbon cycle feedbacks can be neglected even for supervolcanic eruptions: The ensemble mean atmospheric $\mathrm{CO}_{2}$ decrease by about $6 \mathrm{ppm}$ needs to be put in relation to a transient climate sensitivity of $2.2 \mathrm{~K}$ for a doubling of $\mathrm{CO}_{2}$ for the MPI-ESM. (Note that the transient climate sensitivity is much weaker than the equilibrium climate sensitivity, which is $3.4 \mathrm{~K}$ for the MPI-ESM). With regard to the linear carbon cycle-climate feedback analysis that has been performed in the C4MIP framework (Friedlingstein et al., 2006; Roy et al., 2011) one needs to keep in mind that the temperature anomalies in the volcano experiments are not caused by $\mathrm{CO}_{2}$, but by the volcanic aerosols. In our experiment only the volcano-induced changes of atmospheric $p \mathrm{CO}_{2}$ are potentially driving a carbon cycle-climate feedback. These are much smaller than those caused by anthropogenic emissions, i.e., $\max 8 \mathrm{ppm}$ vs. several hundreds of ppm. It is, therefore, that the carbon cycle-climate feedback provides only a negligible fraction of the climate response to a volcanic eruption: For the MPI-ESM a change of $6 \mathrm{ppmv}$ in atmospheric $\mathrm{CO}_{2}$ 
would lead to a temperature change of only about $0.02 \mathrm{~K}$. Even assuming that the perturbation lasts long enough for the equilibrium climate sensitivity of the model $(3.4 \mathrm{~K})$ to be relevant, the feedback-caused temperature decrease would only be around $0.03 \mathrm{~K}$, which is negligible compared to the simulated range of temperature decrease $(3.3 \mathrm{~K}-4.3 \mathrm{~K})$ and even to the variations arising from different initial conditions $(1 \mathrm{~K})$. We, thus, contradict the statement of Frölicher et al. (2011) that their simulated decrease in atmospheric $\mathrm{CO}_{2}$ leads to a significant cooling and perturbs the Earth System on time scales much longer than the residence time of the volcanic aerosols - the perturbations are simply too small to be relevant in this regard.

\subsection{Potential relevance of the composition and size of volcanic ash and of the season and location of eruption}

With regard to the marine carbon cycle, we do not take into account any fertilisation of the marine biology from iron, or other coatings of volcanic ashes, as it has been suggested for smaller scale eruptions (e.g., Watson, 1997; Duggen et al., 2007). After smaller scale volcanic eruptions, such as from Mt. Pinatubo or Cerro Hudson, the fine ash is deposited within weeks and relatively close to the source region (Niemeier et al., 2009), and, therefore, an only local impact on marine biological production is more likely than if the globally spread aerosol cloud would be the source of additional nutrients. Additionally, the release of poisonous substances from the ash coatings might limit the biological production. Since we did not simulate the deposition of fine ash for the supervolcanic eruptions discussed here, we did not include the potential effects of iron in this study.

With regard to the land carbon cycle, we do not take into account tephra (unconsolidated volcanic ash) on land with its potential impact on vegetation and albedo, on land and sea ice. The large caldera forming eruptions at Yellowstone have spread volcanic ash over large parts of the North American continents covering $1 / 3$ of the US with a tephra layer (e.g., Perkins and Nash, 2002; Sparks et al., 2005; Jones et al., 2007). In sensitivity experiments, we investigated the impact of tephra on the carbon cycle for a Yellowstone summer eruption including tephra and found no significant global impact. This agrees with the simulation by Jones et al. (2005), who could show that the ash blanket from Yellowstone has a significant impact on atmospheric circulation, but not on the global climate.

Furthermore, the employed terrestrial vegetation model does not take into account higher photosynthesis rates due to more diffuse radiation that may occur due to higher aerosol loadings after volcanic eruptions (Gu et al., 2003) or caused by anthropogenic emissions of aerosols (Mercado et al., 2009). Using evidence from tree rings, however, Krakauer and Randerson (2003) did not find enhanced NPP following volcanic eruptions, and also Angert et al. (2004) rejected the hypothesis that NPP due to more diffuse radiation could have increased after the Mt. Pinatubo eruption. This implies that neglecting the diffuse radiation impact on plant growth does not severely limit our study.

Finally, the location and season of the eruption may also have an impact on the response of the climate system. We also analysed a smaller ensemble of a Yellowstone-like winter eruption and YTT summer and winter eruptions. This analysis indicates that with regard to the very large eruption investigated here the impact of the latitude of the eruption (Northern Hemisphere vs. tropics) on the carbon cycle is only small (about $0.5 \mathrm{ppm}$ for the maximum perturbation of atmospheric $p \mathrm{CO}_{2}$ between ensemble means, figure not shown). Also the season of the eruption (summer vs. winter) has a similarly small impact. Overall, the deviations from varying location and season of the volcanic eruption are smaller than the spread of the ENSO-based ensemble analysed here (4 ppm).

\section{Conclusions}

In this study, we investigated the simulated response of climate and the carbon cycle to a Yellowstone-like super volcanic eruption with a fully comprehensive ESM. In response to AOD perturbations representing a Yellowstone volcanic super eruption, the simulated global mean surface temperature dropped by between $3.3 \mathrm{~K}-4.3 \mathrm{~K}$ for different ensemble members. The response is strongly asymmetric, with much stronger cooling over the Northern Hemisphere land surface (up to $-10 \mathrm{~K}$ ) than over the Southern Hemisphere sea surface (less than $-2 \mathrm{~K}$ over large regions of the Southern Ocean). Consequently, the terrestrial carbon cycle experiences a stronger perturbation than the marine carbon cycle.

The terrestrial carbon cycle initially responds with a negative anomaly of the vegetation carbon pool in response to the decrease in radiation and temperature. After 2 years this is overruled by an increase of carbon in the soil pool due to decreasing temperature and, hence, reduced respiration of organic matter in the soil. For the marine carbon cycle, we analyse an increase in solubility and a decrease of biological production in the first few years. An interesting feature here is, that not only the biological export production decreases for some years, but also that there is a delay of the planktonic spring bloom in mid-to-high latitudes in both hemispheres, with possible impacts on higher trophic levels. After a few years, the ocean turns into a carbon source for the atmosphere as atmospheric $p \mathrm{CO}_{2}$ decreases in response to the land's soil pool gain. The long-term response of the system is a weak flow from the ocean to the atmosphere, set by the time scale of respiration in the land slow soil pool. At the end of the integration, 200 years after the eruption, both components did not return to pre-eruption levels.

The response of the carbon cycle to the volcanic eruption can be described by 4 phases: In the first two years, the 
land biosphere pool is decreased in response to the reduced short-wave radiation and temperature. During year 2-3 the ocean and soil take up carbon in response to the cooling. From year 4-20, the soil carbon pool increases due to still negative temperature anomalies, and the ocean releases carbon to compensate for reduced atmospheric $p \mathrm{CO}_{2}$ caused by the soil carbon pool increase. After year 20, the soil carbon pool slowly releases the additional carbon after temperatures returned to pre-eruption levels, and the ocean slowly gains back previously released carbon. The equilibrium state after 200 years is slightly different from before the eruption.

For the $100 \times$ Mt. Pinatubo Yellowstone eruption, the complex interaction of the different carbon cycle compartment's response leads to unexpectedly low, close to zero, atmospheric $p \mathrm{CO}_{2}$ perturbations in the first four years after the eruption. Only with a delay of about 5 years atmospheric $p \mathrm{CO}_{2}$ perturbations become larger than for smaller scale eruptions. This would make it difficult to identify supervolcanic eruptions in $\mathrm{CO}_{2}$ records from ice cores even if these could resolve time sufficiently well.

Acknowledgements. This work benefits from stimulating discussions within the MPIM Super Volcano and Millennium projects. We wish to thank Chris Jones for his constructive review. J.S. acknowledges funding from the CliSAP excellence cluster at the KlimaCampus Hamburg, C.T. financial support by the German Science Foundation (DFG, Collaborative Research Centre 574). Computations were carried out at the German Climate Computing Centre (DKRZ).

The service charges for this open access publication have been covered by the Max Planck Society.

Edited by: L. Bopp

\section{References}

Ambrose, S. H.: Late Pleistocene human population bottlenecks, volcanic winter, and differentiation of modern humans, J. Hum. Evol., 34, 623-651, 1998.

Ammann, C., Meehl, G., Washington, W., and Zender, C.: A monthly and latitudinally varying volcanic forcing dataset in simulations of 20th century climate, Geophys. Res. Lett., 30, 16571671, doi:10.1029/2003GL016875, 2003.

Angert, A., Biraud, S., Bonfils, C., Buermann, W., and Fung, I.: $\mathrm{CO} 2$ seasonality indicates origins of post-Pinatubo sink, Geophys. Res. Lett., 31, L11 103, doi:doi:10.1029/2004/GL019760, 2004.

Bondeau, A., Kicklighter, D., Kaduk, J., and The Participants of the Potsdam NPP Model Intercomparison: Comparing global models of terrestrial net primary productivity (NPP): importance of vegetation structure on seasonal NPP estimates., Global Change Biology, 5 (Suppl. 1), 35-45, 1999.
Broecker, W. S. and Peng, T. H., eds.: Tracers in the sea, LamontDoherty Geological Observatory, Columbia Univerity, N.Y., 1982.

Brovkin, V., Lorenz, S., Jungclaus, J., Raddatz, T., Timmreck, C., Reick, C., Segschneider, J., and Six, K.: Sensitivity of a coupled climate-carbon cycle model to large volcanic eruptions during the last millennium, Tellus B, 62B, 674-681, 2010.

Duggen, S., Croot, P., Schacht, U., and Hoffmann, L.: Subduction zone volcanic ash can fertilize the surface ocean and stimulate plankton growth: Evidence from biogeochemical experiments and satellite data, Geophys. Res. Lett., 34, LO1612, doi:10.1029/2006GL027522, 2007.

Friedlingstein, P., Cox, P., Betts, R., Bopp, L., von Bloh, W., Brovkin, V., Cadule, P., Doney, S., Eby, M., Fung, I., Bala, G., John, J., Jones, C., Joos, F., Kato, T., Kawamiya, M., Knorr, W., Lindsay, K., Matthews, H., Raddatz, T., Rayner, P., Reick, C., Roeckner, E., Schnitzler, K.-G., Schnur, R., Strassmann, K., Weaver, A. J., Yoshikawa, C., and Zeng, N.: Climate-carbon cycle feedback analysis: Results from the C4MIP model intercomparison, J. Climate, 19, 3337-3353, 2006.

Frölicher, T., Joos, F., and Raible, C.: Sensitivity of atmospheric $\mathrm{CO}_{2}$ and climate to explosive volcanic eruptions, Biogeosciences, 8, 2317-2339, 2011, http://www.biogeosciences.net/8/2317/2011/.

Gu, L., Baldocchi, D., Wofsy, S., Munger, J., Michalsky, J., Urbanski, S., and Boden, T.: Response of a deciduous forest to the Mount Pinatubo eruption: Enhanced Photosynthesis, Science, 299, 2035-2038, 2003.

Jones, C. and Cox, P.: Modelling the volcanic signal in the atmsospheric $\mathrm{CO}_{2}$ record, Global Biogeochem. Cyc., 15, 453-465, 2001.

Jones, G., Gregory, J., Stott, P., Tett, S., and Thorpe, R.: An AOGCM simulation of the climate response to a volcanic supereruption, Clim. Dyn., 25, 725-773, 2005.

Jones, M., Sparks, R., and Valdes, P.: The climatic impact of supervolcanic ash blankets., Clim. Dyn., 29, 553-564, doi:10.1007/s00382-007-0248-7, 2007.

Jungclaus, J., Lorenz, S., Timmreck, C., Reick, C., Brovkin, V., Six, K., Segschneider, J., Giorgetta, M., Crowley, T., Pongratz, J., Krivova, N., Vieira, L., Solanki, S., Klocke, D., Botzet, M., Esch, M., Gayler, V., Haak, H., Raddatz, T., Roeckner, E., Schnur, R., Widmann, H., Claussen, M., Stevens, B., and Marotzke, J.: Climate and carbon-cycle variability over the last millennium, Clim. Past, 6, 723-737, doi:10.5194/cp-6-723-2010, 2010.

Krakauer, N. and Randerson, J.: Do volcanic eruptions enhance or diminish net primary production? Evidence from tree rings, Global Biogeochemical Cycles, 17, 1118, doi:10.1029/2003GB002076, 2003.

Maier-Reimer, E.: Geochemical cycles in an ocean general circulation model: Preindustrial tracer distributions, Global Biogeochem. Cycles, 7, 645-677, 1993.

Maier-Reimer, E., Kriest, I., Segschneider, J., and Wetzel, P.: The HAMburg Ocean Carbon Cycle model HAMOCC5.1 - Technical description Release 1.1, Reports on Earth System Science 14, Max Planck Institute for Meteorology, 2005.

Marsland, S. J., Haak, H., Jungclaus, J., Latif, M., and Röske, F.: The Max Planck Institute global ocean/sea ice model with orthogonal curvilinear coordinates, Ocean Modell., 5, 91-127, 2003. 
Mercado, L., Bellouin, N., Sitch, S., Boucher, B., Huntingford, C., Wild, M., and Cox, P.: Impact of changes in diffuse radiation on the global land carbon sink, Nature, 458, 1014-1019, doi:10.1038/nature07949, 2009.

Nemani, R., Keeling, C., Hashimoto, H., Jolly, W., Piper, S., Tucker, C., Myneni, R., and Running, S.: Climate-driven increases in global terrestrial net primary production from 1982 to 1999 , Science, 300, 1560-1563, doi:10.1126/science.1082750, 2003.

Niemeier, U., Timmreck, C., Graf, H., Kinne, S., Rast, S., and Self, S.: Initial fate of fine ash and sulfur from large volcanic eruptions, Atmos. Chem. Phys., 9, 9043-9057, 2009, http://www.atmos-chem-phys.net/9/9043/2009/.

Norby, R., DeLucia, E., Gielen, B., Calfapietra, C., Giardina, C., King, J., Ledford, J., McCarthy, H., Moore, D., Ceulemans, R., Angelis, P. D., Finzi, A., Karnosky, D., Kubiske, M., Lukac, M., Pregitzer, K., Scarascia-Mugnozza, G., Schlesinger, W., and Oren, R.: Forest response to elevated $\mathrm{CO}_{2}$ is conserved across a broad range of productivity, PNAS, 102, 18 052-18 056, 2005.

Oppenheimer, C.: Ice core and palaeoclimatic evidence for the timing and nature of the great mid-13th century volcanic eruption, Int. J. Climatol., 23, 417-426, 2003.

Penland, C., Sun, D.-Z., Capotondi, A., and Vimont, D. J.: A brief introduction to El Niño and La Niña. In Climate Dynamics: Why does climate vary?, Geoph. Monog. Series, 189, 53-64, doi:10.1029/2008GM000846, 2010.

Perkins, M. and Nash, B.: Explosive silicic volcanism of the Yellowstone hotspot: the ash fall tuff record., Geol. Soc. Am. Bull., 114(3), 367-381, 2002.

Raddatz, T. J., Reick, C. J., Knorr, W., Kattge, J., Roeckner, E., Schnur, R., Schnitzler, K.-G., Wetzel, P., and Jungclaus, J.: Will the tropical land biosphere dominate the climate - carbon cycle feedback during the twenty-first century?, Clim. Dyn., 29, 565574, 2007.

Read, W. G., Froidevaux, L., and Waters, J. W.: Microwave limb sounder measurements of 25 stratospheric SO2 from the Mt. Pinatubo volcano, Geophys. Res. Lett., 20, 1299-1302, 1993.

Robock, A., Ammann, C., Oman, L., Shindell, D., Levis, S., and Stenchikov, G.: Did the Toba volcanic eruption of 74 ka B.P. produce widespread glaciation?, J. Geophys. Res., p. 114:D10107, doi:10.1029/2008JD011652, 2009.

Roeckner, E., Bäuml, G., Bonaventura, L., Brokopf, R., and Esch, M.: The atmospheric general circulation model ECHAM5. Part I: model description, Report 349, Max Planck Institute for Meteorology, 2003.

Rothenberg, D., Mahowald, N., Lindsay, K., Doney, S., Moore, J., and Thornton, P.: Volcano impacts on climate and biogeochemistry in a coupled carbon-climate model, Earth Syst. Dynam. Discuss., 3, 279-323, 2012.

Roy, T., Bopp, L., Gehlen, M., Schneider, B., Cadule, P., Frölicher, T., Segschneider, J., Tjiputra, J., Heinze, C., and Joos, F.: Regional impacts of climate change and atmospheric $\mathrm{CO}_{2}$ on future ocean carbon uptake: A multi-model linear feedback analysis, J. Climate, 24, 2300-2318, 2011.
Self, S.: The effects and consequences of very large explosive volcanic eruptions, Philosophical Transactions of the Royal Society, A 364, 2073-2097, 2006.

Self, S. and Blake, S.: Consequences of explosive supereruptions, Elements, 4, 41-46, 2008.

Six, K. and Maier-Reimer, E.: Effects of plankton dynamics on seasonal carbon fluxes in a ocean general circulation model, Global Biogeochem. Cycles, 10, 559-583, 1996.

Sparks, R., Self, S., Grattan, J., Oppenheimer, C., Pyle, D., and Rymer, H.: Supereruptions: global effects and future threats., Geological Society of London, www.geolsoc.org.uk/ supereruptions, 2005.

Thompson, D., Wallace, J., Jones, P., and Kennedy, J.: Identifying signatures of natural climate variability in time series of globalmean surface temperature: Methodology and insights, J. Clim., 22, 6120-6141, 2009.

Timmreck, C. and Graf, H.: The initial dispersal and radiative forcing of a Northern Hemisphere mid-latitude super volcano: a model study, Atmos. Chem. Phys., 6, 35-49, 2006, http://www.atmos-chem-phys.net/6/35/2006/.

Timmreck, C., Graf, H., Lorenz, S., Niemeier, U., Zanchettin, D., Matei, D., Jungclaus, J., and Crowley, T.: Aerosol size confines climate response to volcanic super-eruptions, Geophys. Res. Let., 37, L24 705, 5PP., doi:10.1029/2010GL045464, 2010.

Timmreck, C., Graf, H., Zanchettin, D., Hagemann, S., Kleinen, T., and Krüger, K.: Climate response to the Toba super-eruption: regional changes., Quarternary International, 258, 30-44, 2012.

Tjiputra, J. and Ottera, O.: Role of volcanic forcing on future global carbon cycle, Earth Syst. Dynam., 2, 53-67, 2011.

Watson, A.: Volcanic iron, $\mathrm{CO}_{2}$, ocean productivity and climate, Nature, 385, 587-588, 1997.

Wicks, C., Thatcher, W., Dzurisin, D., and Svarc, J.: Uplift, thermal unrest and magma intrusion at Yellowstone caldera, Nature, 440, 72-75, http://dx.doi.org/10.1038/nature04507, 2006.

Williams, M. A. J., Ambrose, S. H., van der Kaars, S., Ruehlemann, C., Chattopadhyaya, U., Pal, J., and Chauhan, P. R.: Environmental impact of the $73 \mathrm{ka}$ Toba super-eruption in South Asia, Palaeoclimatol., Palaeoecol., Palaeogeogr., 284, 295-314, 2009.

Winguth, A. M. E., Heimann, M., Kurz, K. D., Maier-Reimer, E., Mikolajewicz, U., and Segschneider, J.: El Niño-Southern Oscillation related fluctuations of the marine carbon cycle, Glob. Biogeochem. Cyc., 8, 39-63, 1994.

Zanchettin, D., Timmreck, C., Graf, H.-F., Rubino, A., Lorenz, S., Lohmann, K., Krüger, K., and Jungclaus, J.: Bi-decadal variability excited in the coupled ocean-atmosphere system by strong tropical volcanic eruptions, Climate Dynamics, doi:10.1007/s00382-011-1167-1, http://www.springerlink.com/ content/0819r76851376012/fulltext.pdf, 2011. 